\title{
Anticoagulants in Older Patients with Nonvalvular Atrial Fibrillation after Intracranial Hemorrhage
}

\author{
Sylvie Perreault, ${ }^{\mathrm{a}}$ Robert Côté, ${ }^{\mathrm{b}}$ Brian White-Guay, ${ }^{\mathrm{c}}$ Marc Dorais, ${ }^{\mathrm{d}}$ Essaïd Oussaïd, ${ }^{\mathrm{a}}$ Mireille E. Schnitzer ${ }^{\mathrm{a}}$ \\ ${ }^{a}$ Faculty of Pharmacy, University of Montreal, Montreal, QC, Canada \\ ${ }^{b}$ Department of Neurology and Neurosurgery, McGill University, Montreal, OC, Canada \\ 'Faculty of Medicine, University of Montreal, Montreal, QC, Canada \\ ¿StatScience Inc., Notre-Dame-de-l'Île-Perrot, OC, Canada
}

Background and Purpose Patients with nonvalvular atrial fibrillation (NVAF) who survive an intracranial hemorrhage (ICH) have an increased risk of ischemic stroke and systemic embolism (IS/ SE). We investigated whether starting oral anticoagulants (OACs) among older NVAF patients after an ICH was associated with a lower risk of IS/SE and mortality but offset by an increase in major bleeding.

Methods We assembled a patient cohort from the Quebec Régie de l'Assurance Maladie du Québec (RAMQ) and Med-Echo administrative databases. We identified older adults with NVAF from 1995 to 2015. All patients with incident ICH and discharged in community were included. Patients were categorized according to OAC exposure. Outcomes included IS/SE, all-cause mortality, recurrent $\mathrm{ICH}$ and major bleeding after a quarantine period of 6 weeks. Crude event rates were calculated at 1-year of follow-up, and Cox proportional hazard models with a time-dependent binary exposure were used to assess adjusted hazard ratios (AHRs).

Results The cohort of 683 NVAF patients with ICH aged 83 years on average. The rates (per 100 person-years) for IS/SE, death, ICH and major bleeding were 3.3, 40.6, 11.4, and 2.7 for the no OAC group; and 2.6, 16.3, 5.2, and 5.2 for OAC group, respectively. The AHR for IS/SE and death was 0.10 (95\% confidence interval [Cl], 0.05 to 0.21$), 0.43(95 \% \mathrm{Cl}, 0.19$ to 0.97$)$ for recurrent $\mathrm{ICH}$ and 1.73 ( $95 \% \mathrm{Cl}, 0.71$ to 4.20 ) for major extracranial bleeding comparing OAC exposure to non-exposed.

Conclusions Initiating OAC after ICH in older individuals with NVAF is associated with a reduction of IS/SE and mortality and a trend in recurrent ICH supporting its use after ICH.
Correspondence: Sylvie Perreault Faculty of Pharmacy, University of Montreal, Case Postale 6128, Succursale Centre-Ville, Montreal, QC H3C 3J7, Canada

Tel: +1-514-343-6111 (ext 3149)

Fax: +1-514-343-6120

E-mail: sylvie.perreault@umontreal.ca

Received: August 11, 2018

Revised: November 28, 2018

Accepted: January 7, 2019

Keywords Anticoagulants; Atrial fibrillation; Intracranial hemorrhages

\section{Introduction}

Atrial fibrillation (AF) is a cause of ischemic stroke (IS) and is expected to increase in prevalence in the coming years. ${ }^{1}$ In addition, ISs associated with AF are more severe and carry a higher mortality rate. ${ }^{2}$ Oral anticoagulant (OAC) therapy, either vitamin $\mathrm{K}$ antagonists (VKA) or direct oral anticoagulants (DOAC), has been shown to be efficacious in preventing ischemic events including strokes in $\mathrm{AF}^{3-5}$ However, one of the most feared and life-threatening complications of OAC therapy is intracranial hemorrhage (ICH), ${ }^{6}$ and though the risk is less with DOACs, it is still present. This leads to a therapeutic dilemma which is to either avoid use of OAC in patients with $\mathrm{AF}$ after an $\mathrm{ICH}$ to reduce the risk of recurrent $\mathrm{ICH}$ or prescribe $\mathrm{OAC}$ to reduce the risk of 
IS or systemic embolism (SE). Present guidelines for ICH have not provided any clear recommendations because of a paucity of evidence in this area, and also by the lack of randomized controlled trials for this unmet need, since previous ICH was an exclusion criterion for all randomized clinical trials that tested anticoagulation in patients with $\mathrm{AF}^{7,8}$

However, recent observational studies, ${ }^{9-12}$ and meta-analyses $^{13-16}$ have suggested that the use of OAC after an ICH was associated with a reduction in all-cause mortality and ischemic events although in some reports, ${ }^{17,18}$ a higher rate of recurrent ICH was noted. Using Quebec healthcare databases, we evaluated the risk and benefits of OAC use after an ICH in older patients with nonvalvular atrial fibrillation (NVAF). We use timedependent modeling in order to relate recent and current exposure to OAC on the occurrence of events.

\section{Methods}

\section{Data source}

We assembled a cohort from administrative databases (hospital discharges [Med-Echo], medical services and public drug plan), administered by the Régie de l'Assurance Maladie du Québec (RAMO). The databases were linked through encrypted health insurance numbers. Information from these databases provided a complete picture of hospital admissions. The protocol received the approval of the University of Montreal Ethics Committee.

\section{Population-based cohort}

From a random sample of $40 \%$ of a larger cohort for the period January 1, 1995 to December 31, 2015, we identified older individuals (over 65 years) who were discharged alive with a primary or secondary diagnosis of NVAF (International Classification of Diseases [ICD]-9 427.3, 427.31, 427.32, or ICD-10 I48). The follow-up period for the cohort ended in December 2016.

Patients with an incident ICH (ICD-9: 430, 431, 432.x, 852.x 853.x; ICD-10: I60-I62, S063C, S064-S066) requiring admission to a hospital were included. Patients with an $\mathrm{ICH}$ or complication (ICD-9: 438.9; ICD-10: I690-692) in the 5 years before AF diagnosis were excluded. Patients needed to be on the RAMQ drug plan continuously for 12 months prior to the index $\mathrm{ICH}$ and during follow-up.

Patients were followed after a quarantine period of 6 weeks after hospital discharge for their ICH. This period was chosen to ensure that events during follow-up could reasonably be attributed to the treatment regimens rather than sub-optimal management of the initial coagulation abnormalities, or consequences from ICH complications. Patients on dual therapy (OAC and antiplatelet) or antiplatelet only were excluded.

\section{Choice of the index date}

The index date was defined as the date of the incident ICH (ICD-9: 430, 431, 432.x, 852.x, 853.x; or ICD-10: I60-I62, S063C, S064-S066). We then identified patients who filled a claim of warfarin or DOAC within 1 year after hospital discharge and who were living in the community. Patients were followed for 1 year or until the occurrence of the following censoring events: outcome, claim of antiplatelet dual-treatment, end of study or death, whichever came first.

\section{Exposure to OAC treatment}

At discharge from hospital and after the 6-week period quarantine, patients were classified by treatment regimens as OAC treatment (VKA/DOAC) or no OAC treatment. In order to investigate outcomes under different overall exposure levels, we categorized the patient population into three types: those who were treated continuously, variably, and never during the follow-up. Firstly, time-dependent exposures were defined firstly as a binary exposure variable, indicating the patient's current exposure status (yes/no), and secondly as a categorical exposure variable indicating (1) a mean possession ratio (MPR) of $\geq 90 \%$ over the past 6 weeks; (2) MPR $<90 \%$ over the past 6 weeks and exposed on the day of the event; (3) MPR $<90 \%$ over the past 6 weeks and not exposed on the day of the event; or (4) never exposed over the past 6 weeks (reference). These two time-dependent exposures were evaluated at each week of follow-up, allowing for exposure to vary overtime for the same individual.

\section{Outcome measures}

The main analysis focused on the primary outcome including, IS/SE and all-cause mortality (Supplementary Table 1). Secondary analyses were performed separately for IS/SE, recurrent $\mathrm{ICH}$, major extracranial bleeding, and all-cause mortality (Supplementary Table 1). We also reported the combination of IS/SE and recurrent $\mathrm{ICH}$, the combination of death and recurrent $\mathrm{ICH}$ or the combination of death and major extracranial bleeding, as a global outcome measure reflecting clinical benefit, using the method proposed by Singer et al..$^{19}$

\section{Patient demographics and clinical characteristics}

Comorbidities were ascertained at the time of ICH hospitalization. Other concomitant medications were defined as filled prescriptions up to 3 months before $\mathrm{ICH}$ hospitalization. The cardiovascular comorbidities and risk of stroke at baseline were evaluated with the $\mathrm{CHA}_{2} \mathrm{DS}_{2}$-VASc score, ${ }_{1}^{20,21}$ and we determined bleeding risk with a modified HAS-BLED score not including international normalized ratio (INR) lability ${ }^{22}$ (Supple- 
mentary Tables 2-4). We assessed comorbidities using the Charlson comorbidity index. ${ }^{23}$

\section{Statistical analyses}

We used descriptive statistics for the demographics and clinical characteristics. For outcome analyses, events were identified and collected starting 6 weeks after hospital discharge for $\mathrm{ICH}$. We depicted the overall 1-year risk of outcomes using KaplanMeier plots for three categories of patient exposure of the time over the total duration of follow-up (not exposed, variably exposed, and continuously exposed [MPR $\geq 90 \%]$ ). The total duration of follow-up was calculated using the follow-up of each patient from baseline until IS/SE, recurrent ICH, major extracranial bleeding, and all-cause mortality or most recent censored follow-up assessment. The period at risk started at 6 weeks after the qualifying event and ended when patients experienced an outcome or the end of follow-up, whichever came first. We calculated crude event rates at 1 year by dividing the number of events occurring during follow-up with the person-years of follow-up for each treatment group (number of events per 100 person-years).

We used a Cox proportional hazards model with a time-dependent binary exposure to contrast the relative risks of an outcome for current OAC use (yes/no), estimating both crude and adjusted hazard ratios (AHRs). The baseline covariates in the adjusted analysis were selected based on the results of univariate and multivariable analyses and most relevant clinical variables (Supplementary Tables 5 and 6).

A second model estimated AHRs for clinical outcomes with a time-dependent categorical exposure as defined above (Supplementary Table 7).

A third model estimated the crude and AHRs for all-cause mortality with the binary time-dependent exposure while also adjusting for time-dependent covariates IS/SE, recurrent ICH, and major extracranial bleedings (Supplementary Table 8). All analyses were performed using SAS version 9.4 (SAS Institute Inc., Cary, NC, USA).

Sub-group analyses were performed for two sub-groups of

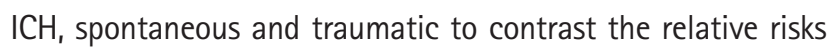
of an outcome between subjects on OAC treatment versus no OAC (sub-groups' definition at the Supplementary Table 9). A sub-group analysis of patients older than 75 years was performed and compared to those under 75 years. The crude and AHRs were estimated using a Cox proportional hazards model with the binary time-dependent exposure.

Finally, we repeated the time-to-event analyses for the outcomes defined as a combination of IS/SE and ICH, death and $\mathrm{ICH}$, and death and extracranial major bleeding, as respective global outcome measures reflecting overall clinical benefit were calculated using the method proposed by Singer et al. ${ }^{19}{ }^{19}$ and we provided 95\% confidence intervals using the Bootstrap method.

\section{Results}

\section{Demographics and clinical characteristics}

The cohort inclusion flow chart and patient characteristics are presented in Table 1 and Figure 1. Among 683 NVAF patients with ICH, 423 (61.9\%) had no OAC exposure and 260 (38.1\%) were exposed to OACs to some extent. Of the complete cohort, $148(21.7 \%)$ were partially exposed and $115(16.8 \%)$ were continuously exposed. Among the 260 patients who filled out an OAC prescription, $82.3 \%$ were initiated on warfarin, the mean age was 81.7 years, and $46.1 \%$ were men. In the same exposed subset, co-morbidities were as follows: ischemic heart disease (64.6\%), hypertension (83.8\%), heart failure $(40.0 \%)$, diabetes (31.1\%), dyslipidemia (50.0\%), chronic renal disease (40.4\%), peripheral vascular disease (25.0\%), and previous stroke/transient ischemic attack (49.6\%). Mean CHA2DS2-VASc and HASBLED scores were 3.9 and 2.6, respectively (Table 1). The patient characteristics according to OAC exposure categories were quite similar to those not exposed (Supplementary Table 10).

\section{Exposure to OAC treatment}

Among those who were exposed to OAC treatment, the proportions of patients exposed to several adherence levels defined as $\geq 90 \%$, between $\geq 80 \%$ and $<90 \%$, between $\geq 70 \%$ and $<80 \%$, between $\geq 60 \%$ and $<70 \%$, and those $<60 \%$ were at $44.6 \%, 11.9 \%, 8.5 \%, 7.3 \%$, and $27.7 \%$, respectively.

\section{IS/SE and all-cause mortality}

Median follow-up was 12 months. The Kaplan Meier curves for clinical outcomes during follow-up are presented in Figure 2. The overall unadjusted yearly rates for the primary outcome of combined end points of IS/SE and all-cause mortality for patients with any OAC exposure versus no exposure were 17.9 versus 43.1 per 100 person-years (Table 2). The Cox proportional hazards model with binary time-dependent exposure yielded an AHR 0.10 (range, 0.05 to 0.21 ) (Figure 3). The AHR for the categorical time-dependent exposure of $\geq 90 \%$ was at $0.10(0.04$ to 0.24$)$, with similar results for the category of exposure $<90 \%$ and being exposed at the time of event. In contrast, for the category of exposure $<90 \%$ and not being exposed, the risk of IS/SE and all-cause mortality was significantly increased (AHR, 2.43 [1.56 to 3.78]) relative to no exposure.

The overall unadjusted yearly rates for IS/SE for the group of any $\mathrm{OAC}$ exposure versus no exposure were 2.6 versus 3.3 per 
Total of patients in RAMQ database

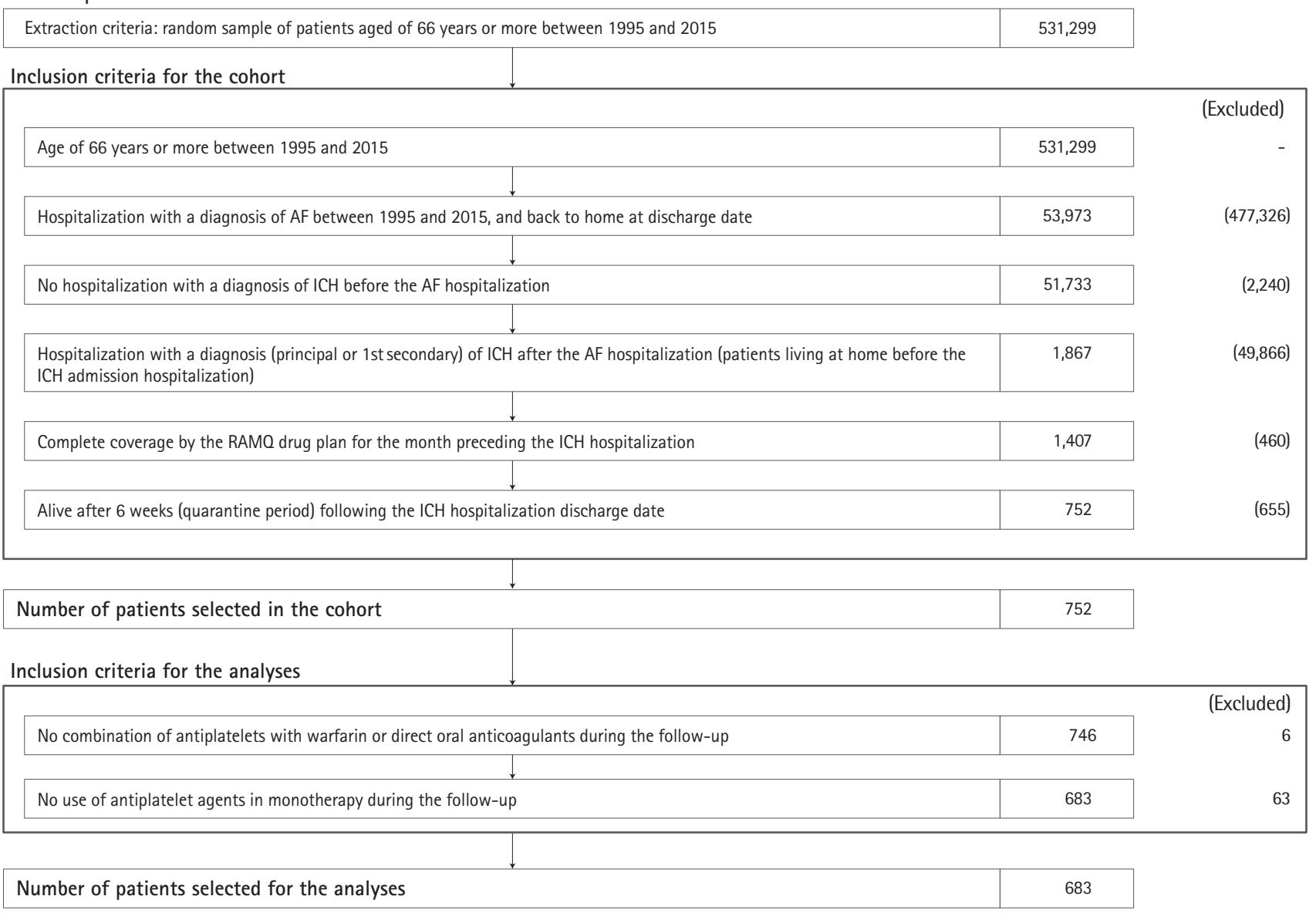

Figure 1. Flow chart of study design and patients of the study cohort. AF, atrial fibrillation; ICH, intracranial hemorrhage; RAMQ, Régie de I'Assurance Maladie du Quebec.

Table 1. Baseline characteristics of full cohort for a quarantine period of 6 weeks

\begin{tabular}{|c|c|c|c|}
\hline Characteristic & No treatment $(n=423)$ & OACs exposure $(n=260)$ & $P$ \\
\hline \multicolumn{4}{|l|}{ Sociodemographics* } \\
\hline Age (yr) & $83.6 \pm 5.8$ & $81.7 \pm 5.8$ & $<0.0001$ \\
\hline Male sex & $200(47.3)$ & $120(46.1)$ & 0.77 \\
\hline \multicolumn{4}{|c|}{ Prior exposure (3-mo prior ICH index) } \\
\hline Anticoagulants & $292(69.0)$ & $233(89.6)$ & $<0.0001$ \\
\hline Warfarine & $280(66.2)$ & $214(82.3)$ & $<0.0001$ \\
\hline DOACS & $14(3.3)$ & $21(8.1)$ & $<0.01$ \\
\hline Antiplatelet agents & $167(39.5)$ & $83(31.9)$ & 0.04 \\
\hline ASA low dose & $155(36.6)$ & $74(28.5)$ & 0.03 \\
\hline Clopidrogrel & $27(6.4)$ & $18(6.9)$ & 0.78 \\
\hline \multicolumn{4}{|c|}{ Co-morbidities (ICH index and 1-yr prior) } \\
\hline Hypertension & $366(86.5)$ & $218(83.8)$ & 0.33 \\
\hline Dyslipidemia & $152(35.9)$ & $130(50.0)$ & $<0.001$ \\
\hline Diabetes & $130(30.7)$ & $81(31.1)$ & 0.91 \\
\hline Coronary artery disease & $272(64.3)$ & $168(64.6)$ & 0.93 \\
\hline
\end{tabular}


Table 1. Continued

\begin{tabular}{|c|c|c|c|}
\hline Characteristic & No treatment $(n=423)$ & OACs exposure $(n=260)$ & $P$ \\
\hline Acute myocardial infarction & $27(6.4)$ & $21(8.1)$ & 0.40 \\
\hline Chronic heart failure & $147(34.7)$ & $104(40.0)$ & 0.17 \\
\hline Cerebrovascular disease including TIA in 5-yr period & $231(54.6)$ & $129(49.6)$ & 0.20 \\
\hline Peripheral vascular disease & $85(20.1)$ & $65(25.0)$ & 0.13 \\
\hline Chronic renal failure & $168(39.7)$ & $105(40.4)$ & 0.86 \\
\hline Acute renal failure & $75(17.7)$ & $40(15.4)$ & 0.42 \\
\hline Chronic obstructive pulmonary disease/asthma & $130(30.7)$ & $78(30.0)$ & 0.84 \\
\hline Prior major bleeding (excluding $\mathrm{ICH}$ ) in 5-yr period & $39(9.2)$ & $27(10.4)$ & 0.62 \\
\hline Liver disease & $10(2.4)$ & $7(2.7)$ & 0.79 \\
\hline Systemic embolism & $5(1.2)$ & $5(1.9)$ & 0.43 \\
\hline \multicolumn{4}{|l|}{ Medications (3-mo prior ICH index) ${ }^{+}$} \\
\hline$\beta$-Blockers & $245(57.9)$ & $157(60.4)$ & 0.52 \\
\hline Calcium channel blockers & $161(38.1)$ & $109(41.9)$ & 0.32 \\
\hline Inhibitors of renin-angiotensin system & $206(48.7)$ & $126(48.5)$ & 0.95 \\
\hline Diuretics & $229(54.1)$ & $152(58.5)$ & 0.27 \\
\hline Loop diuretics & $193(45.6)$ & $122(46.9)$ & 0.74 \\
\hline Statin & $202(47.7)$ & $149(57.3)$ & 0.02 \\
\hline Antidiabetics & $98(23.2)$ & $69(26.5)$ & 0.32 \\
\hline Antidepressants & $105(24.8)$ & $56(21.5)$ & 0.33 \\
\hline Proton pump inhibitors & $198(46.8)$ & $132(50.8)$ & 0.31 \\
\hline Digoxin & $99(23.4)$ & $80(30.8)$ & 0.03 \\
\hline Amiodarone & 49 (11.6) & $39(15.0)$ & 0.20 \\
\hline $\mathrm{CHA}_{2} \mathrm{DS}_{2}$-VASc score $(\mathrm{ICH} \text { index and 1-yr prior })^{+}$ & $3.9 \pm 1.3$ & $3.9 \pm 1.3$ & 0.59 \\
\hline 1 & $1(0.2)$ & $7(2.7)$ & \\
\hline 2 & $53(12.5)$ & $20(7.7)$ & \\
\hline 3 & $110(26.0)$ & $72(27.7)$ & \\
\hline $4-9$ & $259(61.2)$ & $161(61.9)$ & \\
\hline HAS-BLED score $(\mathrm{ICH} \text { index and 1-yr prior })^{\dagger}$ & $2.6 \pm 1.1$ & $2.6 \pm 1.1$ & 0.80 \\
\hline$<3.0$ & $219(51.8)$ & $141(54.2)$ & 053 \\
\hline$\geq 3.0$ & $204(48.2)$ & $119(45.8)$ & 0.00 \\
\hline \multicolumn{4}{|l|}{ Charlson score $(\mathrm{ICH} \text { index and 1-yr prior index })^{+}$} \\
\hline Mean \pm SD & $4.5 \pm 3.2$ & $4.3 \pm 3.2$ & 0.50 \\
\hline Median (interquartile range) & $4.0(2.0-6.0)$ & $4.0(2.0-6.0)$ & \\
\hline \multicolumn{4}{|l|}{ Health medical service (1-yr prior ICH index) ${ }^{+}$} \\
\hline No. of specialty visits & $9.9 \pm 19.3$ & $9.3 \pm 14.8$ & 0.42 \\
\hline No. of family physician visits & $3.2 \pm 6.0$ & $2.7 \pm 4.4$ & 0.38 \\
\hline No. of emergency visits & $3.9 \pm 3.8$ & $3.6 \pm 3.6$ & 0.31 \\
\hline \multicolumn{4}{|l|}{ Health hospital service $\left(3-y r\right.$ prior ICH index) ${ }^{+}$} \\
\hline Proportion of all-cause hospital admission & $360(85.1)$ & $226(86.9)$ & 0.51 \\
\hline No. of all-cause hospital admission & $2.7 \pm 2.4$ & $2.7 \pm 2.5$ & 0.91 \\
\hline Hospital length of stay & $11.2 \pm 10.8$ & $7.5 \pm 6.9$ & $<0.0001$ \\
\hline
\end{tabular}

Values are presented as mean \pm standard deviation or number (\%) unless otherwise indicated.

$\mathrm{OAC}$, oral anticoagulant; ICH, intracranial hemorrhage; DOAC, direct oral anticoagulant; ASA, acetylsalicylic acid; TIA, transient ischemic attack.

${ }^{*}$ At the cohort entry; ${ }^{\dagger}$ Data source: Régie de l'Assurance Maladie du Quebec (RAMO) dataset; ${ }^{*}$ The components of the scores are provided in Supplementary Tables. 
Ischemic stroke or systemic embolism

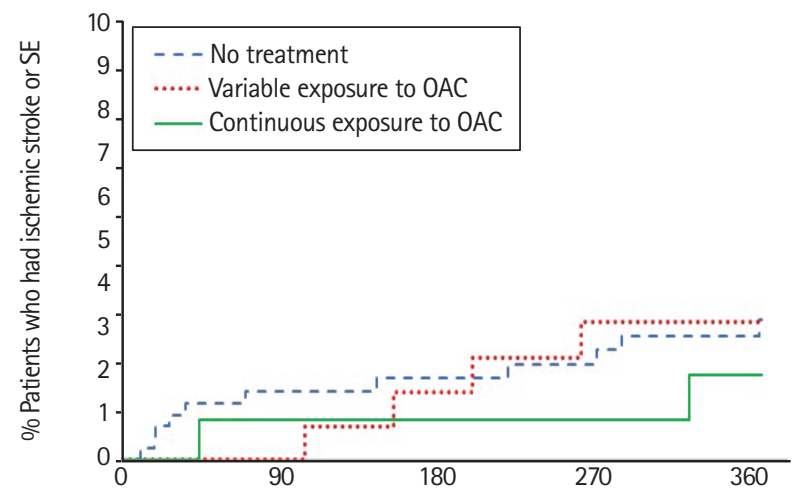

No. at risk

Duration of follow-up (day)

$\begin{array}{llllll}\text { No tx } & 422 & 357 & 331 & 304 & 280 \\ \text { Partial } & 145 & 137 & 129 & 121 & 118 \\ \text { Contin. } 115 & 109 & 106 & 101 & 100\end{array}$

Recurrent intracranial bleeding

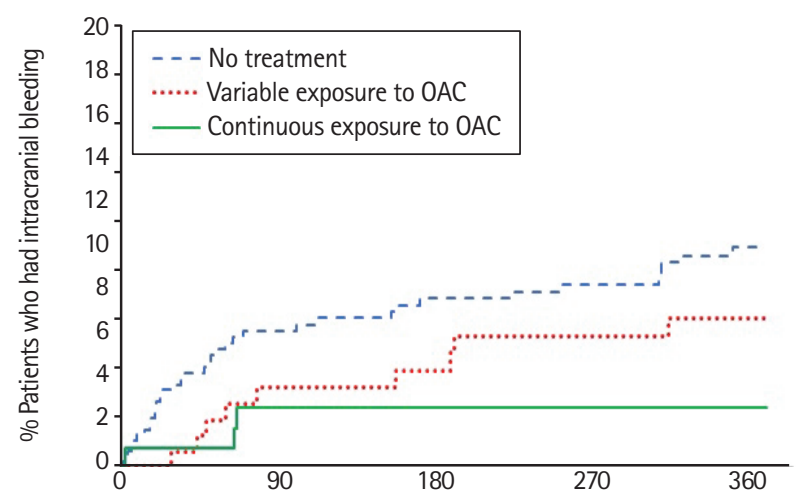

No. at risk Duration of follow-up (day)

$\begin{array}{lllll}\text { No tx } 423 & 339 & 312 & 287 & 262 \\ \text { Partial } 144 & 131 & 124 & 116 & 114 \\ \text { Contin. } 116 & 108 & 105 & 100 & 100\end{array}$
All-cause mortality

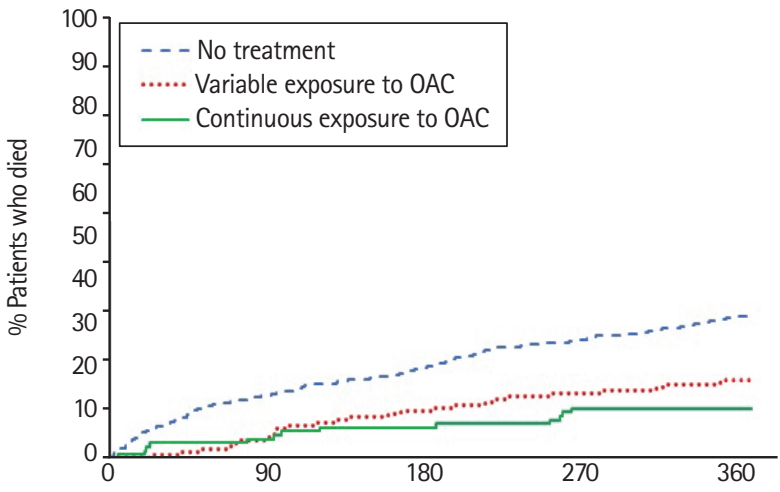

No. at risk

Duration of follow-up (day)

$\begin{array}{lllll}\text { No tx } 418 & 358 & 331 & 305 & 283\end{array}$

$\begin{array}{llll}\text { Partial } 148 & 140 & 132 & 126\end{array}$

$\begin{array}{lllll}\text { Contin. } 115 & 110 & 107 & 102 & 102\end{array}$

Major extracranial bleeding

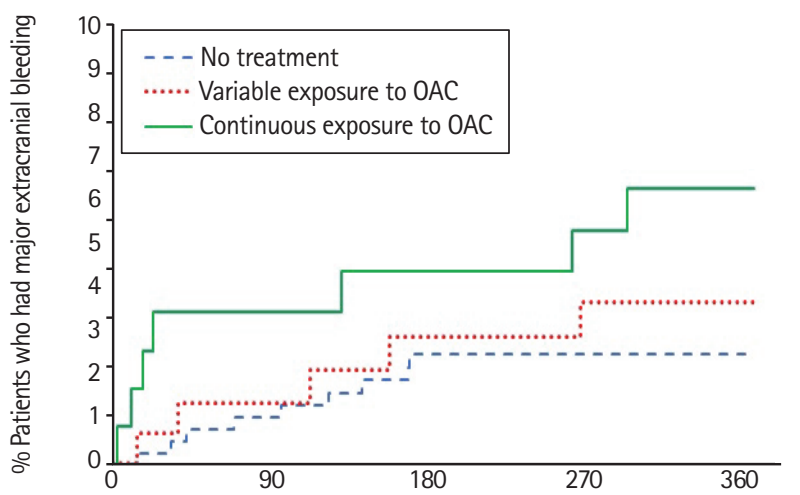

No. at risk Duration of follow-up (day)

$\begin{array}{lllll}\text { No tx } & 419 & 355 & 324 & 300\end{array}$

$\begin{array}{lllll}\text { Partial } & 145 & 135 & 126 & 119\end{array}$

$\begin{array}{lllll}\text { Contin. } 117 & 108 & 104 & 99\end{array}$

Figure 2. Kaplan-Meier for outcomes during the 1-year period following hospital discharge. (A) Ischemic stroke or systemic embolism. (B) All-cause mortality. (C) Recurrent intracranial bleeding. (D) Major extracranial bleeding. SE, systemic embolism; OAC, oral anticoagulant; tx, treatment is defined as a variable or continuous exposure to OAC; Contin., continuous.

100 person-years. As shown in Figure 2, the main model with binary time-dependent exposure yielded non-significant AHRs, as for all categorical time-dependent exposures. For all-cause mortality, any OAC exposure versus no exposure yielded 16.3 versus 40.6 per 100 person-years. The main model with binary time-dependent exposure gave an AHR 0.07 (0.03 to 0.17) (Figure 3). The AHR for binary and categorical time-dependent exposure of $\geq 90 \%$ was 0.04 (0.01 to 0.17 ), which is the range of the point estimate of the category of exposure $<90 \%$ and being exposed at the time of event. In contrast, in the category of exposure $<90 \%$ and not being exposed at the time of event, the risk of mortality was significantly higher (AHR, 2.43 [1.55 to 3.82]).
Finally, in the analysis where we adjusted for IS/SE, recurrent $\mathrm{ICH}$ and major extracranial bleeding, the estimated treatment effect of the binary time-dependent exposure was unchanged (AHR, 0.07 [0.03 to 0.17]) (Supplementary Table 8).

\section{Recurrence of $\mathrm{ICH}$ and major extracranial bleeding}

The unadjusted yearly rates for $\mathrm{ICH}$ recurrence for the group of any $\mathrm{OAC}$ exposure versus no exposure were 5.2 versus 11.4 per 100 person-years. The Cox proportional hazards model with binary time-dependent exposure yielded an AHR 0.43 (0.19 to 0.97) (Figure 3). The trend in the AHR for the categorical time- 
Table 2. Rate of clinical events per categories of OAC exposure during 1-year period of follow-up for a quarantine period of 6 weeks

\begin{tabular}{|c|c|c|c|c|}
\hline Variable & $\begin{array}{c}\text { No anticoagulant and } \\
\text { no antiplatelet }\end{array}$ & $\begin{array}{l}\text { All OACs } \\
\text { exposure }\end{array}$ & $\begin{array}{c}\text { OACs } \\
\text { partial exposure }\end{array}$ & $\begin{array}{l}\text { OACs } \\
\text { continuous exposure }\end{array}$ \\
\hline Stroke (ischemic only)/SE and all cause-mortality & 422 & 260 & 145 & 115 \\
\hline Events & 143 & 42 & 27 & 15 \\
\hline Time to event, mean (median) (day) & $135(104)$ & $148(123)$ & $155(136)$ & $135(97)$ \\
\hline Person-time (yr) & 331.9 & 235.0 & 129.4 & 105.6 \\
\hline Event rate (/100 person-years) & 43.1 & 17.9 & 20.9 & 14.2 \\
\hline Stroke (ischemic only)/SE & 422 & 260 & 145 & 115 \\
\hline Events & 11 & 6 & 4 & 2 \\
\hline Time to event, mean (median) (day) & $133(70)$ & $181(177)$ & $180(177)$ & $184(184)$ \\
\hline Person-time (yr) & 331.9 & 235.0 & 129.4 & 105.6 \\
\hline Event rate (/100 person-years) & 3.3 & 2.6 & 3.1 & 1.9 \\
\hline All-cause mortality & 418 & 263 & 148 & 115 \\
\hline Events & 135 & 39 & 26 & 13 \\
\hline Time to event, mean (median) (day) & $135(109)$ & 146 (119) & $155(131)$ & $128(97)$ \\
\hline Person-time (yr) & 332.8 & 239.6 & 133.0 & 106.6 \\
\hline Event rate (/100 person-years) & 40.6 & 16.3 & 19.5 & 12.2 \\
\hline Recurrent intracranial bleeding & 423 & 260 & 144 & 116 \\
\hline Events & 36 & 12 & 9 & 3 \\
\hline Time to event, mean (median) (day) & $95(48)$ & $102(64)$ & $121(77)$ & $44(64)$ \\
\hline Person-time (yr) & 315.7 & 229.5 & 124.6 & 104.9 \\
\hline Event rate (/100 person-years) & 11.4 & 5.2 & 7.2 & 2.9 \\
\hline Major extracranial bleeding & 419 & 262 & 145 & 117 \\
\hline Events & 9 & 12 & 5 & 7 \\
\hline Time to event, mean (median) (day) & $95(96)$ & $110(74)$ & $117(112)$ & $105(23)$ \\
\hline Person-time (yr) & 328.9 & 231.2 & 127.3 & 103.9 \\
\hline Event rate (/100 person-years) & 2.7 & 5.2 & 3.9 & 6.7 \\
\hline
\end{tabular}

OAC, oral anticoagulant; $\mathrm{SE}$, systemic embolism.

dependent exposure of $\geq 90 \%$ was 0.38 ( 0.13 to 1.08 ), close to that of the category of exposure less than $90 \%$ and being exposed at the time of event. And, in the category of exposure less than $90 \%$ and not being exposed at the time of event, the AHR was null (AHR, 1.00 [0.30 to 3.26]). But, for major extracranial bleeding risk, the group of OACs exposure versus no exposure was 5.2 versus 2.7 per 100 person-years; and, a trend of increasing risk can be observed across all the categories of OAC exposure.

\section{Subgroup analyses}

The rates of clinical events per exposure category are presented in Table 3. For spontaneous and traumatic $\mathrm{ICH}$ analyses, we used a time-to-event analysis to contrast the relative risks of an outcome between exposure groups. For spontaneous and traumatic ICH, AHRs for the composite of IS/SE and all-cause mortality for OACs exposure versus no OAC were 0.10 (0.04 to 0.27 ) and 0.11 ( 0.04 to 0.30 ), respectively; for all-cause mortality, those estimates were 0.08 (0.03 to 0.25 ) and 0.06 (0.01 to 0.23); for recurrent $\mathrm{ICH}$, those estimates were $0.34(0.10$ to 1.14 ) and 0.53 ( 0.18 to 1.60$)$; and for major extracranial bleeding, those estimates were 1.67 (0.48 to 5.79) and 1.66 ( 0.46 to 5.97), respectively (Supplementary Table 11). Finally, we still observed similar results for the sub-group of patients older than 75 years old (Supplementary Table 12).

\section{Net clinical benefit}

The adjusted net clinical benefit for OACs exposure for the total cohort, and broken down into spontaneous or traumatic ICH are depicted in Figure 4 and the Supplementary Tables 1315. The OAC exposure is associated with a better net clinical benefit. 


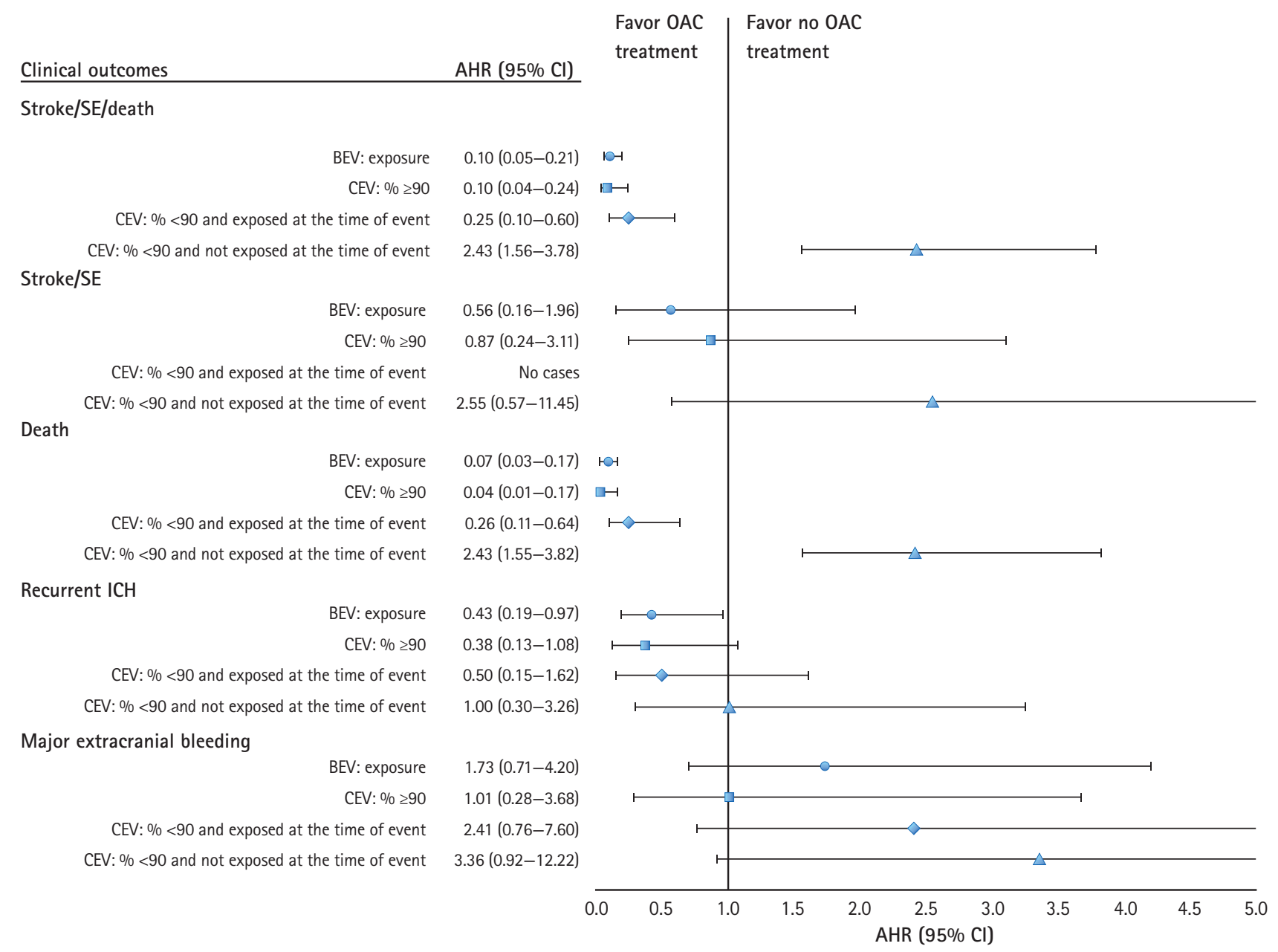

Figure 3. Forest plots of adjusted hazard ratios (AHRs) for binary exposure, and categorical exposure and being exposed or not exposed at the time of the event using time-dependent model during a 1-year of follow-up. OAC, oral anticoagulant; $\mathrm{Cl}$, confidence interval; SE, systemic embolism; BEV, binary exposure variable; $\mathrm{CEV}$, categorical exposure variable; ICH, intracranial hemorrhage.

\section{Discussion}

In this study of older individuals diagnosed with NVAF who experienced an $\mathrm{ICH}$, our main findings include (1) a high adherence level of OAC after an ICH was significantly associated with a reduction in the combined outcome of IS/SE and allcause mortality; (2) all-cause mortality as a single outcome was significantly lower for those with high OAC adherence level in contrast with IS/SE events; (3) no significant difference was observed between the two sub-groups of spontaneous ICH or traumatic $\mathrm{ICH}_{\text {; }}$ (4) similar results were observed the subgroup of patients older than 75 years; (5) the risk of major extracranial hemorrhages was not significant but the point estimate suggested a trend in increased risk among OAC groups; and (6) the net clinical benefit which included all IS/SE and recurrent ICH showed a significant benefit in favor of OAC treatment when compared to the no OAC group, and the estimated benefits were even more extreme for the outcomes of all-cause mortality and recurrent ICH or major extracranial bleeding.

Our finding of significantly lower IS/SE and all-cause mortality as a combined outcome in regularly OAC treated NVAF individuals after an $\mathrm{ICH}$ is similar to previous recent reports. ${ }^{10-12,15-17}$ In our study, this beneficial effect appears to be mostly driven by a strong reduction in mortality rather than by a reduction in IS/SE. Similar to our own results, two other studies ${ }^{10,17}$ reported a non-significant reduction in IS/SE. This in part may possibly be due to the smaller number of IS/SE versus death in these populations; as an example, in the study by Nielsen et al. ${ }^{17}$ mortality events were more than five times more frequent than thromboembolic events and in our own study they were 10 times more frequent. This explanation is also indirectly supported by the study of Chao et al. ${ }^{9}$ in which the beneficial effect of OAC therapy in preventing IS as a single outcome was based on a very large number of cerebral ischemic events $(n=1,094)$. 
Table 3. Rate of clinical events per categories of OAC exposure during 1-year period of follow-up for a quarantine period of 6 weeks for spontaneous and traumatic intracranial hemorrhage

\begin{tabular}{|c|c|c|c|c|}
\hline \multirow[b]{2}{*}{ Variable } & \multicolumn{2}{|c|}{ Spontaneous } & \multicolumn{2}{|c|}{ Traumatic } \\
\hline & $\begin{array}{c}\text { No anticoagulant and no } \\
\text { antiplatelet }\end{array}$ & $\begin{array}{l}\text { OACs } \\
\text { all exposure }\end{array}$ & $\begin{array}{c}\text { No anticoagulant and no } \\
\text { antiplatelet }\end{array}$ & $\begin{array}{c}\text { OACs } \\
\text { all exposure }\end{array}$ \\
\hline Stroke (ischemic only)/SE and all cause-mortality & 247 & 125 & 175 & 135 \\
\hline Events & 85 & 21 & 58 & 21 \\
\hline Time to event, mean (median) (day) & $135(104)$ & $157(136)$ & 135 (104) & 139 (118) \\
\hline Person-time (yr) & 193.4 & 113.0 & 138.4 & 122.0 \\
\hline Event rate (/100 person-years) & 43.9 & 18.6 & 41.9 & 17.2 \\
\hline Stroke (ischemic only)/SE & 247 & 125 & 175 & 135 \\
\hline Events & 7 & 1 & 4 & 5 \\
\hline Time to event, mean (median) (day) & $143(70)$ & $262(262)$ & $117(82)$ & $165(155)$ \\
\hline Person-time (yr) & 193.4 & 113.0 & 138.4 & 122.0 \\
\hline Event rate (/100 person-years) & 3.6 & 0.9 & 2.9 & 4.1 \\
\hline All-cause mortality & 246 & 125 & 172 & 138 \\
\hline Events & 80 & 20 & 55 & 19 \\
\hline Time to event, mean (median) (day) & $133(107)$ & $152(128)$ & $137(110)$ & $140(118)$ \\
\hline Person-time (yr) & 195.2 & 113.3 & 137.6 & 126.3 \\
\hline Event rate (/100 person-years) & 41.0 & 17.7 & 40.0 & 15.0 \\
\hline Recurrent intracranial bleeding & 249 & 123 & 174 & 137 \\
\hline Events & 23 & 4 & 13 & 8 \\
\hline Time to event, mean (median) (day) & $110(54)$ & $120(71)$ & $68(34)$ & $93(62)$ \\
\hline Person-time (yr) & 185.7 & 109.6 & 130.0 & 119.9 \\
\hline Event rate (/100 person-years) & 12.4 & 3.6 & 10.0 & 6.7 \\
\hline Major extracranial bleeding & 246 & 125 & 173 & 137 \\
\hline Events & 6 & 5 & 3 & 7 \\
\hline Time to event, mean (median) (day) & $104(106)$ & $137(130)$ & 78 (96) & $91(37)$ \\
\hline Person-time (yr) & 192.4 & 110.5 & 136.5 & 120.7 \\
\hline Event rate (/100 person-years) & 3.1 & 4.5 & 2.2 & 5.8 \\
\hline
\end{tabular}

OAC, oral anticoagulant; $\mathrm{SE}$, systemic embolism.

Similar to previous studies, ${ }^{9,11,13}$ we found no significant difference in outcomes for the sub-group of spontaneous ICH compared to traumatic ICH, although this differs from the report by Nielsen et al., ${ }^{17}$ in which resumption of OAC therapy was associated with a reduced risk of recurrent $\mathrm{ICH}$ in the traumatic ICH group only. As well, another study ${ }^{10}$ reported a significant reduced risk for recurrence of $\mathrm{ICH}$ for patients treated with OAC if the quarantine period was 4 weeks or less after $\mathrm{ICH}$ hospitalization. A potential explanation for this finding could be that patients on an OAC have more regular medical follow-ups related to their need for control of anticoagulation (INR) and consequently better control of relevant risk factors such as hypertension which could in turn result in a reduced risk of recurrent ICH. Alternatively, imbalances of unmeasured variables which could be linked with a higher likelihood of OAC treatment and smaller risk of $\mathrm{ICH}$ recurrence (size and location of ICH) could lead to confounding bias. Again, only a minority of patients were prescribed OAC treatment, and it is likely that these patients may be at higher risk of IS/SE or lower risk of recurrent ICH compared to those not exposed. The severity of ICH could bias the association with resumption of OAC treatment by the indication bias. And, the patients having extracranial major bleeding seem to have more comorbidities, as suggested by crude and AHRs (Supplementary Tables 5 and 6). Finally, the relative proportion of spontaneous vs traumatic $\mathrm{ICH}$ within the ICH population studied could influence results if both groups don't present the same inherent recurrence risk for $\mathrm{ICH}$.

In addition, we decided to include as an outcome the combination of IS/SE and recurrent ICH, all cause of death and recurrent $\mathrm{ICH}$, and all-cause of death and extracranial bleeding based on the concept of net clinical benefit. ${ }^{19}$ We evaluated the risk-benefit balance in this population which is at a high 
Thromboembolism/intracranial hemorrhage

Total cohort $7.1(6.9-7.3)$

Non-traumatic diagnosis $11.8(11.5-12.0)$

Traumatic diagnosis $2.1(1.9-2.4)$

All-cause death/intracranial hemorrhage

Total cohort 30.9 (30.6-31.3)

Non-traumatic diagnosis $32.6(32.3-33.1)$

Traumatic diagnosis 28.5 (28.0-29.0)

All-cause death/extracranial major bleeding

Total cohort $22.2(21.8-22.5)$

Non-traumatic diagnosis $22.1(21.7-22.5)$

Traumatic diagnosis $21.6(21.1-22.0)$

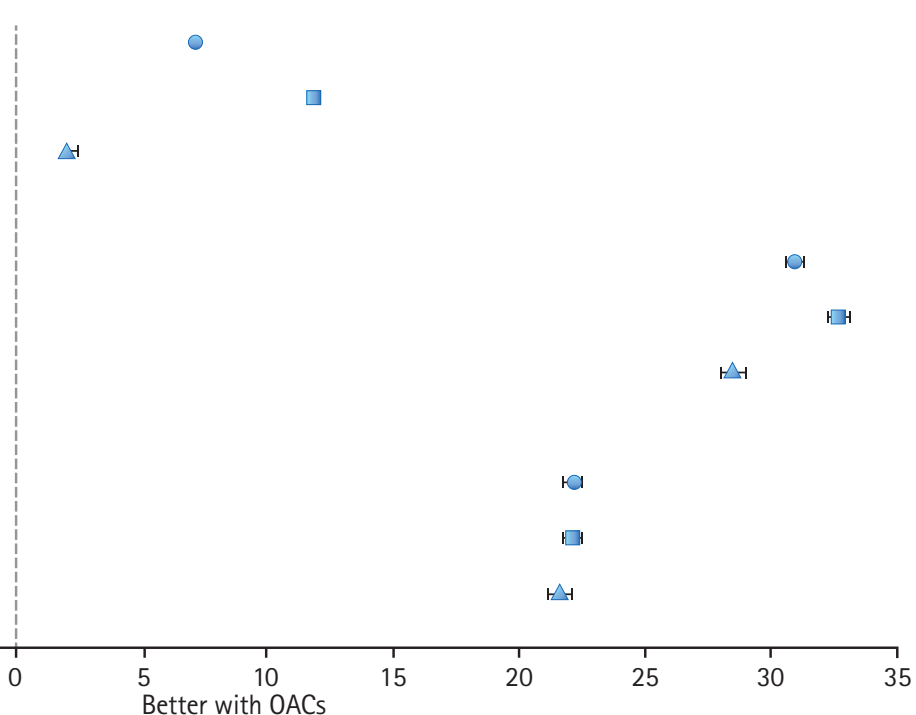

Net clinical benefit, events prevented per 100 person-years

Figure 4. The net clinical benefit (95\% confidence interval) of oral anticoagulant (OAC) exposure compared to no OAC exposure among total cohort and spontaneous (non-traumatic) and traumatic intracranial hemorrhage subcohort.

risk of both disabling and lethal ischemic as well as $\mathrm{ICH}$ or extracranial major bleeding events. Based on the adjusted net clinical benefit for OAC exposure for the total cohort, and also broken down into spontaneous or traumatic ICH, we found better net clinical benefits in favor of the OAC treatment compared to not being exposed.

In contrast to previous studies, we included time-dependent categorical exposure groups which consider the recent history of OAC exposure. Globally, partial recent exposure and not currently being exposed did not show any significant benefit for any of the outcomes, when compared to the no OAC exposure group. This observation suggests that the benefits of $O A C$ treatment can be achieved through OAC adherence or a more optimal patient management of OAC exposure. We choose not to include patients treated with antiplatelet agents since previous randomized trials ${ }^{24}$ and observational studies ${ }^{9,10}$ did not report any benefit for these agents.

Our study presents several positive aspects, some of these include a relatively large and well characterized Canadian population-based cohort, inclusion of time-dependent categorical OAC treatment exposure groups during the followup that better characterize real life, and the inclusion of net clinical benefit outcomes which represent a more meaningful picture of the balance between risk and benefit for OAC treated individuals. However, our study has several limitations. First, this observational study using hospital administrative data which does not include all clinically relevant variables (INR stability, functional status, or risk of falls). Second, we had no access to neuroimaging studies to characterize certain relevant clinical variables such as the location (deep vs. lobar) and volume of the $\mathrm{ICH}$, and the presence of specific abnormalities like micro-bleeds which could influence antithrombotic management. ${ }^{25}$ Third, there is also a possibility based on clinical and imaging data that the patients receiving OAC therapy were deemed to be at higher risk of IS/SE or lower risk of recurrent ICH compared to those not exposed. Four, our results may not be generalizable to other groups such as non-hospitalized individuals with NVAF and other ethnic groups as our population was mostly white. ${ }^{26}$ Our results would only partly apply to D0ACs as we only had a small number of individuals treated. Finally, residual bias is possible in regards to unmeasured variables and the healthy population effect.

\section{Conclusions}

In summary, our results support the use of OAC in older patients with NVAF after an ICH, with the benefit of preventing mortality and ischemic events offsetting the risk of $\mathrm{ICH}$ recurrence. There is need for risk stratification for the sub-type of stroke, localization and severity of ICH and OAC exposure level. Giving, that this cohort study may have the residual risk for unmeasured confounding future randomized controlled trials ${ }^{27}$ are required to confirm our results. 


\section{Supplementary materials}

Supplementary materials related to this article can be found online at https://doi.org/10.5853/jos.2018.02243.

\section{Disclosure}

Sylvie Perreault is holding the Sanofi Canada endowment Research Chair in Optimal Drug Use.

\section{Acknowledgments}

The study was funded by the Heart and Stroke Foundation of Canada.

We thank the RAMO and Quebec Health Ministry for assistance in handling the data and the Commission d'accès à l'information for authorizing the study.

\section{References}

1. Colilla $S$, Crow A, Petkun W, Singer DE, Simon T, Liu X. Estimates of current and future incidence and prevalence of atrial fibrillation in the U.S. adult population. Am J Cardiol 2013;112:1142-1147.

2. McGrath ER, Kapral MK, Fang J, Eikelboom JW, Conghaile $A$, Canavan $\mathrm{M}$, et al. Association of atrial fibrillation with mortality and disability after ischemic stroke. Neurology 2013;81: 825-832.

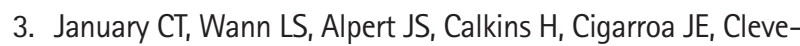
land JC Jr, et al. 2014 AHA/ACC/HRS guideline for the management of patients with atrial fibrillation: a report of the American College of Cardiology/American Heart Association Task Force on Practice Guidelines and the Heart Rhythm Society. J Am Coll Cardiol 2014;64:e1-e76.

4. Hart RG, Pearce LA, Aguilar MI. Meta-analysis: antithrombotic therapy to prevent stroke in patients who have nonvalvular atrial fibrillation. Ann Intern Med 2007;146:857-867.

5. Culebras A, Messé SR. Summary of evidence-based guideline update: prevention of stroke in nonvalvular atrial fibrillation: report of the Guideline Development Subcommittee of the American Academy of Neurology. Neurology 2014;83:1220.

6. Alonso A, Bengtson LG, MacLehose RF, Lutsey PL, Chen LY, Lakshminarayan $\mathrm{K}$. Intracranial hemorrhage mortality in atrial fibrillation patients treated with dabigatran or warfarin. Stroke 2014:45:2286-2291.

7. Hemphill JC 3rd, Greenberg SM, Anderson CS, Becker K, Bendok BR, Cushman $M$, et al. Guidelines for the management of spontaneous intracerebral hemorrhage: a guideline for healthcare professionals from the American Heart Association/American Stroke Association. Stroke 2015;46:20322060.

8. Steiner T, Al-Shahi Salman R, Beer R, Christensen H, Cordonnier C, Csiba L, et al. European Stroke Organisation (ESO) guidelines for the management of spontaneous intracerebral hemorrhage. Int J Stroke 2014;9:840-855.

9. Chao TF, Liu CJ, Liao JN, Wang KL, Lin YJ, Chang SL, et al. Use of oral anticoagulants for stroke prevention in patients with atrial fibrillation who have a history of intracranial hemorrhage. Circulation 2016;133:1540-1547.

10. Nielsen PB, Larsen TB, Skjøth F, Gorst-Rasmussen A, Rasmussen LH, Lip GY. Restarting anticoagulant treatment after intracranial hemorrhage in patients with atrial fibrillation and the impact on recurrent stroke, mortality, and bleeding: a nationwide cohort study. Circulation 2015;132:517-525.

11. Kuramatsu JB, Gerner ST, Schellinger PD, Glahn J, Endres M, Sobesky J, et al. Anticoagulant reversal, blood pressure levels, and anticoagulant resumption in patients with anticoagulation-related intracerebral hemorrhage. JAMA 2015;313:824836.

12. Biffi A, Kuramatsu JB, Leasure A, Kamel H, Kourkoulis $C$,

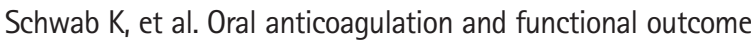
after intracerebral hemorrhage. Ann Neurol 2017;82:755-765.

13. Murthy SB, Gupta A, Merkler AE, Navi BB, Mandava P, ladecola $C$, et al. Restarting anticoagulant therapy after intracranial hemorrhage: a systematic review and meta-analysis. Stroke 2017;48:1594-1600.

14. Korompoki E, Filippidis F, Nielsen PB, Del Giudice A, Lip GYH, Kuramatsu $\mathrm{JB}$, et al. Long-term antithrombotic treatment in intracranial hemorrhage survivors with atrial fibrillation. $\mathrm{Neu}$ rology 2017;89:687-696.

15. Hawkes MA, Rabinstein AA. Anticoagulation for atrial fibrillation after intracranial hemorrhage: a systematic review. Neurol Clin Pract 2018;8:48-57.

16. Zhou Z, Yu J, Carcel C, Delcourt C, Shan J, Lindley RI, et al. Resuming anticoagulants after anticoagulation-associated intracranial haemorrhage: systematic review and meta-analysis. BMJ Open 2018;8:e019672.

17. Nielsen PB, Larsen TB, Skjøth F, Lip GY. Outcomes associated with resuming warfarin treatment after hemorrhagic stroke or traumatic intracranial hemorrhage in patients with atrial fibrillation. JAMA Intern Med 2017;177:563-570.

18. Poli D, Antonucci E, Dentali F, Erba N, Testa S, Tiraferri E, et al. Recurrence of ICH after resumption of anticoagulation with VK antagonists: CHIRONE study. Neurology 2014;82:10201026.

19. Singer $D E$, Chang $Y$, Fang MC, Borowsky LH, Pomernacki NK, 
Udaltsova $\mathrm{N}$, et al. The net clinical benefit of warfarin anticoagulation in atrial fibrillation. Ann Intern Med 2009;151:297305.

20. Lip GY, Nieuwlaat R, Pisters R, Lane DA, Crijns HJ. Refining clinical risk stratification for predicting stroke and thromboembolism in atrial fibrillation using a novel risk factor-based approach: the euro heart survey on atrial fibrillation. Chest 2010;137:263-272.

21. Friberg L, Rosenqvist M, Lip GY. Evaluation of risk stratification schemes for ischaemic stroke and bleeding in 182678 patients with atrial fibrillation: the Swedish Atrial Fibrillation cohort study. Eur Heart J 2012;33:1500-1510.

22. Pisters $R$, Lane DA, Nieuwlaat $R$, de Vos CB, Crijns HJ, Lip GY. A novel user-friendly score (HAS-BLED) to assess 1-year risk of major bleeding in patients with atrial fibrillation: the Euro Heart Survey. Chest 2010;138:1093-1100.

23. Deyo RA, Cherkin DC, Ciol MA. Adapting a clinical comorbidity index for use with ICD-9-CM administrative databases. J
Clin Epidemiol 1992;45:613-619.

24. Vanassche T, Lauw MN, Eikelboom JW, Healey JS, Hart RG, Alings $M$, et al. Risk of ischaemic stroke according to pattern of atrial fibrillation: analysis of 6563 aspirin-treated patients in ACTIVE-A and AVERROES. Eur Heart J 2015;36:281-287a.

25. Stoker TB, Evans NR. Managing risk after intracerebral hemorrhage in concomitant atrial fibrillation and cerebral amyloid angiopathy. Stroke 2016;47:e190-e192.

26. Shen AY, Yao JF, Brar SS, Jorgensen MB, Chen W. Racial/ethnic differences in the risk of intracranial hemorrhage among patients with atrial fibrillation. J Am Coll Cardiol 2007;50:309315.

27. van Nieuwenhuizen KM, van der Worp HB, Algra A, Kappelle $\sqcup$, Rinkel GJ, van Gelder IC, et al. Apixaban versus Antiplatelet drugs or no antithrombotic drugs after anticoagulationassociated intraCerebral HaEmorrhage in patients with Atrial Fibrillation (APACHE-AF): study protocol for a randomised controlled trial. Trials 2015;16:393. 
Supplementary Table 1. Definition of variables outcomes according to ICD-9 and ICD-10 from Med-Echo databases

\begin{tabular}{|c|c|c|}
\hline & ICD-9 codes & ICD-10 codes \\
\hline \multicolumn{3}{|l|}{ Thromboembolic events } \\
\hline \multicolumn{3}{|l|}{ Stroke } \\
\hline Ischaemic stroke & $\begin{array}{l}\text { 433.xx, } 434 . x x, 436.0,436.9 \text { (primary diagnosis only } \\
\text { using Med-Echo) }\end{array}$ & $\begin{array}{l}\text { I63 except I63.6, I64 (primary diagnosis only using } \\
\text { Med-Echo) }\end{array}$ \\
\hline Systemic embolism & $\begin{array}{l}\text { 444.x, 557.0, 362.31, 362.32, } 598.31 \text { (primary diagnosis } \\
\text { only using Med-Echo) }\end{array}$ & 174 (primary only) \\
\hline Arterial embolism and thrombosis & 444.x (primary diagnosis only using Med-Echo) & $\begin{array}{l}\text { 174.0, I74.1, I74.2, 174.3, 174.5, I74.8, } 174.9 \text { (primary } \\
\text { diagnosis only using Med-Echo) }\end{array}$ \\
\hline $\begin{array}{l}\text { Ischemic colitis or mesenteric thrombo- } \\
\text { embolism }\end{array}$ & 557.0 (primary diagnosis only using Med-Echo) & K55.0 (primary diagnosis only using Med-Echo) \\
\hline Retinal artery thromboembolism & $\begin{array}{l}\text { 362.31, } 362.32 \text { (primary diagnosis only using Med- } \\
\text { Echo) }\end{array}$ & H34.1, H34.2 (primary diagnosis only using Med-Echo) \\
\hline Renal artery thromboembolism & 593.81 (primary diagnosis only using Med-Echo) & N28.0 (primary diagnosis only using Med-Echo) \\
\hline \multicolumn{3}{|l|}{ All-cause of deaths } \\
\hline \multicolumn{3}{|l|}{ Major bleeding } \\
\hline Intracranial bleeding (recurrent event) & $\begin{array}{l}430,431,432 . x, 852 . x, 853 . x \text { (primary diagnosis or the } \\
\text { first secondary diagnosis using Med-Echo) }\end{array}$ & $\begin{array}{l}\text { I60, I61, I62, S06.3, S06.4, S06.5, S06.6 (primary diag- } \\
\text { nosis or the first secondary diagnosis using Med- } \\
\text { Echo) }\end{array}$ \\
\hline \multicolumn{3}{|l|}{ Other major bleeding } \\
\hline \multicolumn{3}{|l|}{ Major GI bleeding } \\
\hline $\begin{array}{l}\text { Upper gastrointestinal bleeding (only } \\
\text { using Med-Echo) }\end{array}$ & $\begin{array}{l}\text { 456.1, 530.7, 531.0x, 531.2x, 531.4x, 531.6x, 532.0x, } \\
532.2 x, 532.4 x .532 .6 x, 533.0 x .533 .2 x, 533.4 x \\
\text { 533.6x, 534.0x, 534.2x, 534.4x, 534.6x, 535.1, 578.0 } \\
\text { (primary diagnosis only using Med-Echo) }\end{array}$ & $\begin{array}{l}\text { I85.0, K22.6, K25.0, K25.2, K25.4, K25.6, K26.0, K26.2, } \\
\text { K26.4, K26.6, K27.0, K27.2, K27.4, K27.6, K28.0, K28.2, } \\
\text { K28.4, K28.6, K29.0, K92.0 (primary diagnosis only } \\
\text { using Med-Echo) }\end{array}$ \\
\hline $\begin{array}{l}\text { Upper gastrointestinal bleeding (only } \\
\text { using RAMQ) }\end{array}$ & $\begin{array}{l}\text { 456.1, 530.7, 531.0x, 531.2x, 531.4x, 531.6x, 532.0x, } \\
532.2 x, 532.4 x .532 .6 x, 533.0 x, 533.2 x, 533.4 x \\
533.6 x, 534.0 x, 534.2 x, 534.4 x, 534.6 x, 535.1,578.0 \\
\text { RAMQ ICD-9 at an emergency room and procedure } \\
\text { endoscopic control of gastric or duodenal bleeding or } \\
\text { upper gastrointestinal endoscopy including esopha- } \\
\text { gus, stomach, and either the duodenum and/or jeju- } \\
\text { num as appropriate with control of bleeding, any } \\
\text { method (code 00691) within } 7 \text { days }\end{array}$ & $\begin{array}{l}\text { I85.0, K22.6, K25.0, K25.2, K25.4, K25.6, K26.0, K26.2, } \\
\text { K26.4, K26.6, K27.0, K27.2, K27.4, K27.6, K28.0, K28.2, } \\
\text { K28.4, K28.6, K29.0, K92.0 RAMQ ICD-9 at an emer- } \\
\text { gency room and procedure endoscopic control of gas- } \\
\text { tric or duodenal bleeding or upper gastrointestinal } \\
\text { endoscopy including esophagus, stomach, and either } \\
\text { the duodenum and/or jejunum as appropriate with } \\
\text { control of bleeding, any method (00691) within } 7 \\
\text { days }\end{array}$ \\
\hline Lower gastrointestinal bleeding & $\begin{array}{l}562.02,562.03,562.12,562.13,569.3 x, 569.85,578.1 x \\
578.9 \text { (primary diagnosis only using Med-Echo) }\end{array}$ & $\begin{array}{l}\text { K57.11, K57.13, K57.31, K57.33, K62.5, K55.21, K92.1, } \\
\text { K92.2 (primary diagnosis only using Med-Echo) }\end{array}$ \\
\hline \multicolumn{3}{|l|}{ Other major bleeds } \\
\hline Gross hematuria & 599.7 (primary diagnosis only using Med-Echo) & R31 (primary diagnosis only using Med-Echo) \\
\hline Hemoptysis & 786.3x (primary diagnosis only using Med-Echo) & $\begin{array}{l}\text { R04.2, R04.89, R04.9 (primary diagnosis only using } \\
\text { Med-Echo) }\end{array}$ \\
\hline Vitreous hemorrhage & 379.23 (primary diagnosis only using Med-Echo) & H43.13 (primary diagnosis only using Med-Echo) \\
\hline Urogenital bleed & $\begin{array}{l}\text { 626.2x and } 280.0 \text { (primary only), } 285.1 \text { (principal diag- } \\
\text { nosis or the first secondary diagnosis) or } 285.9 \text { (prin- } \\
\text { cipal diagnosis or the first secondary diagnosis using } \\
\text { Med-Echo) }\end{array}$ & $\begin{array}{l}\text { N92.0 and D50.0 (primary only), D62 (principal diagno- } \\
\text { sis or the first secondary diagnosis), D64.9 (principal } \\
\text { diagnosis or the first secondary diagnosis using Med- } \\
\text { Echo) }\end{array}$ \\
\hline Hemathrosis & 719.1x (primary diagnosis only using Med-Echo) & M25.0x (primary diagnosis only using Med-Echo) \\
\hline Hemopericardium & 423.0 (primary diagnosis only using Med-Echo) & I31.2 (primary diagnosis only using Med-Echo) \\
\hline Hemoperitoneum & 568.8 (primary diagnosis only using Med-Echo) & K66.1 (primary diagnosis only using Med-Echo) \\
\hline Hemorrhage not specified & 459.0x (primary diagnosis only using Med-Echo) & R58.0 (primary diagnosis only using Med-Echo) \\
\hline Acute posthemorrhagic anemia & 285.1x (primary diagnosis only using Med-Echo) & D62 (primary diagnosis only using Med-Echo) \\
\hline $\begin{array}{l}\text { Instrumental bleeds codes in addition to } \\
\text { other previous codes }\end{array}$ & $\begin{array}{l}996 x, 997 x, 998 x, 999 x, 8602,8603,8604,8605,851 x \\
920 x, 921 x, 922 x, 923 x, 924 x\end{array}$ & S271x, S272.x \\
\hline
\end{tabular}

ICD, International Classification of Diseases; GI, gastrointestinal; RAMQ, Régie de l'Assurance Maladie du Québec. 
Supplementary Table 2. Risk score definition for $\mathrm{CHA}_{2} \mathrm{DS}_{2}-\mathrm{VASc}$ and Modified HAS-BLED

Risk score definition

Points if present

$\mathrm{CHA}_{2} \mathrm{DS}_{2}$-VASC

Congestive heart failure or left ventricular dysfunction

Hypertension

Age $65-74$ years

Age $\geq 75$ years

Diabetes mellitus

Stroke (ischemic stroke, transient ischemic disease, or systemic embolism)

Vascular disease (myocardial infarction, peripheral arterial disease, or aortic plaque)

Sex category (female)

HAS-BLED

Hypertension

Abnormal renal function

Abnormal hepatic function

Abnormal Stroke (ischemic stroke, transient ischemic disease)

Bleeding

Older than $>65$ years

Labile international normalized ratio (not available)

Drugs (ASA, clopidrogel, prasugrel, ticagrelor, ticlopidine, or non-steroidal anti-inflammatory drugs) in the 1 month preceding the ICH hospitalization or 1 month after discharge

Alcohol intake

ASA, acetylsalicylic acid; ICH, intracranial hemorrhage. 
Supplementary Table 3. Definition of variables used in the risk score definition of $\mathrm{CHA}_{2} \mathrm{DS}_{2}$-VASc according to ICD-9 and ICD-10 from Med-Echo databases

\begin{tabular}{lll}
\hline $\mathrm{CHA}_{2} \mathrm{DS}_{2}$-VASc & \multicolumn{1}{c}{ ICD-9 codes } & \multicolumn{1}{c}{ ICD-10 codes } \\
\hline Congestive heart failure & $402.01,402.11,402.91,404.01,404.11,404.91,404.03$, & I11.0, I13.0, I13.2, I42.0, I50 \\
Left ventricular dysfunction & $404.13,404.93,425.4,428.0$ & I50.1, I50.9 \\
Hypertension & $428.1,428.9$ & I10 \\
Diabetes & 401 & E08, E10, E11, E13 \\
Ischemic stroke & $250 . x$ & I63 except 63.6, I67.89 \\
Systemic embolism & $433 . x x, 434 . x x, 436$ & I74, K55.0, H34.1, H34.2, N28.0 \\
Transient ischemic stroke & $444 . x, 557.0,362.31,362.32,598.31$ & G45 \\
Aortic plaque & $435 . x$ & I70.0 \\
Peripheral arterial disease & 440.0 & I70.1 to I70.9, I71, I73.0, I73.89, I73.9 \\
Myocardial infarction & 440 (except 440.0), 441, 443.0, 443.89, 443.9 & I21, I22, I23
\end{tabular}

ICD, International Classification of Diseases. 
Supplementary Table 4. Definition of variables used in the risk score definition of HAS-BLED based on associated morbidities and concomitant drug

\begin{tabular}{lll}
\hline Modified HASBLEED & ICD-9 & ICD-10 \\
\hline Ischemic stroke & $433 . x x, 434 . x x, 436$ & I63 except I63.6, I67.89 \\
Transient ischemic-attack & $435 . x$ & G45 \\
Moderate to severe renal disease & $404.01,404.03,404.11,404.13,404.91,404.93,580.0$, & I12, I13, N00, N01, N02, N03, N04, N05, N07, N11, \\
& $580.4,581.0,581.1,581.2,581.3,581.89,581.9,582.0$, & N12, N14, N17, N18, N19
\end{tabular}

Moderate to severe liver disease

Haemorrhagic stroke intracranial (non-traumatic)

Extracranial major or unclassified major bleeding

Traumatic intracranial bleeding
Clopidrogel, ticlopidine, prasugrel, tica-
grelor
Low dose ASA
Nonsteroidal anti-inflammatory drugs

Alcohol

$331.7,359.4,425.5,577.1$ 578.0 $578.1 x, 578.9$

Other sites:

Gastrointestinal bleeding $578.1 \mathrm{x}, 578.9$

$852 x, 853 x$
Upper GI: 456.1, 530.7, 531.0x, 531.2x, 531.4x, 531.6x, 532.0x, 532.2x, 532.4x. 532.6x, 533.0x. 533.2x, 533.4x, $533.6 x, 534.0 x, 534.2 x, 534.4 x, 534.6 x, 535.01,537.83$,

Lower GI: 562.02, 562.03, 562.12, 562.13, 569.3x, 569.85,

$626.2 x$ and $280.0,285.1$ or 285.9

599.7, 786.3x, 379.23, 719.1x, 423.0x, 568.8, 459.0x, 285.1x

Upper Gl: 531.0x, 531.2x, 531.4x, 531.6x, 532.0x, 532.2x, 532.4x. 532.6x, 533.0x. 533.2x, 533.4x, 533.6x, 534.0x, $534.2 x, 534.4 x, 534.6 x, 535.01,537.83,578.0$

Lower Gl: 562.02, 562.03, 562.12, 562.13, 569.3x, 569.85,

46486, 47307, 45617, 47402, 47834, 47866

00143, 46353 (daily dose $<100 \mathrm{mg}$ )

46353, 38184, 47327, 47078, 41694, 47059, 43150, 47122, $33803,44749,04745,46654,47506,04810,38691$, 44359, 47385, 47084, 19752, 47890, 07462, 42019 $47346,47107,40381,45592,45407,03766$
K7200, K762, K766, B150, B160, B162, B190, K704, 185

$160,161,162$

Upper GI: I850, K226, K250, K252, K254, K256, K260, K262, K264, K266, K270, K272, K274, K276, K280, K282, K284, K286, K2901,K290, K31811, K920

Lower GI: K921, K922, K5711,K5713, K5731, K5733, K625, K5521

Other sites:

N92.0 and D50.0 or D62 or D64.9,

R31, R042, R0489, R049, H43.13,

M250x, I31.2, K66.1, R58.0, D62

Upper GI: K250, K252, K254, K256, K260, K262, K264, K266, K270, K272, K274, K276, K280, K282, K284, K286, K2901,K290, K31811, K920 Lower Gl: K921, K922, K5711,K5713, K5731, K5733, K625, K5521

S063, S064, S065, S066

46486, 47307, 45617, 47402, 47834, 47866

00143, 46353 (daily dose $<100 \mathrm{mg}$ )

, $38184,47327,47078,41694,47059$ $43150,47122,33803,44749,04745,46654$ $47506,04810,38691,44359,47385,47084$ $19752,47890,07462,42019,47346,47107$, $40381,45592,45407,03766$

E224, E529A, F10, G312, G612, G721, I426, K292, K70, K860, L278A, 0354, T51, Z714, Z721

ICD, International Classification of Diseases; ASA, acetylsalicylic acid. 
Supplementary Table 5. Crude hazard ratios of clinical outcomes with a quarantine period of 6 weeks with binary time-dependent exposure (full cohort)

\begin{tabular}{|c|c|c|c|c|c|}
\hline & $\begin{array}{l}\text { Stroke/SE/death } \\
\text { (185 events) }\end{array}$ & $\begin{array}{c}\text { Stroke/SE } \\
\text { (17 events) }\end{array}$ & $\begin{array}{c}\text { Death } \\
\text { (174 events) }\end{array}$ & $\begin{array}{c}\text { Recurrent intracranial } \\
\text { bleeding } \\
\text { (48 events) }\end{array}$ & $\begin{array}{c}\text { Major extracranial } \\
\text { bleeding } \\
\text { (21 events) }\end{array}$ \\
\hline \multicolumn{6}{|l|}{ Exposure to OACs } \\
\hline \multicolumn{6}{|l|}{ No exposure (reference) } \\
\hline Exposure & $0.11(0.06-0.23)$ & $0.53(0.15-1.85)$ & $0.07(0.03-0.18)$ & $0.45(0.20-1.01)$ & $1.63(0.67-3.95)$ \\
\hline \multicolumn{6}{|l|}{ Age (yr) } \\
\hline \multicolumn{6}{|l|}{ 65-74 (reference) } \\
\hline$\geq 75$ & $2.36(1.25-4.46)$ & $1.03(0.27-4.49)$ & $2.76(1.36-5.62)$ & $0.56(0.27-1.15)$ & $2.94(0.40-21.80)$ \\
\hline \multicolumn{6}{|l|}{ Sex } \\
\hline \multicolumn{6}{|l|}{ Male (reference) } \\
\hline Female & $0.78(0.59-1.03)$ & $4.25(1.23-14.66)$ & $0.72(0.53-0.96)$ & $1.21(0.69-2.11)$ & $2.57(1.02-6.48)$ \\
\hline $\begin{array}{l}\text { Prior thromboembolism } \\
\text { (stroke/TIA/SE)* }\end{array}$ & $1.18(0.73-1.89)$ & $1.35(0.31-5.85)$ & $1.18(0.73-1.93)$ & $0.66(0.21-2.13)$ & $1.52(0.45-5.08)$ \\
\hline Prior major bleeding (except ICH)* & $1.29(0.83-2.01)$ & $1.25(0.29-5.44)$ & $1.32(0.84-2.07)$ & $1.61(0.72-3.57)$ & $3.51(1.39-8.85)$ \\
\hline Chronic heart failure* & $1.69(1.28-2.24)$ & $0.70(0.25-1.96)$ & $1.80(1.35-2.41)$ & $0.88(0.49-1.58)$ & $1.82(0.82-4.07)$ \\
\hline Peripheral artery disease ${ }^{*}$ & $1.07(0.77-1.50)$ & $0.69(0.20-2.37)$ & $1.15(0.82-1.62)$ & $0.73(0.36-1.50)$ & $1.74(0.75-4.07)$ \\
\hline Chronic kidney disease* & $1.68(1.27-2.24)$ & $1.60(0.64-4.04)$ & $1.64(1.23-2.20)$ & $0.91(0.52-1.61)$ & $1.89(0.85-4.23)$ \\
\hline Hypertension* & $0.99(0.66-1.49)$ & $2.74(0.37-20.65)$ & $0.95(0.63-1.44)$ & $0.73(0.36-1.50)$ & $1.76(0.41-7.46)$ \\
\hline Dyslipidemia* & $0.93(0.70-1.24)$ & $0.72(0.27-1.91)$ & $0.90(0.67-1.22)$ & $0.78(0.44-1.39)$ & $2.03(0.90-4.57)$ \\
\hline Diabetes* & $1.31(0.98-1.75)$ & $1.10(0.41-2.93)$ & $1.29(0.95-1.74)$ & $0.66(0.35-1.26)$ & $2.22(1.00-4.94)$ \\
\hline Beta-blockers* & $1.32(0.99-1.77)$ & $0.96(0.38-2.44)$ & $1.36(1.01-1.85)$ & $0.72(0.41-1.24)$ & $1.54(0.66-3.59)$ \\
\hline Statins ${ }^{*}$ & $0.88(0.66-1.17)$ & $1.16(0.46-2.93)$ & $0.84(0.63-1.12)$ & $0.82(0.47-1.42)$ & $1.30(0.58-2.92)$ \\
\hline NSAIDs* & $0.38(0.12-1.18)$ & Not to small & $0.41(0.13-1.28)$ & $1.02(0.25-4.20)$ & $1.04(0.14-7.74)$ \\
\hline Proton-pump inhibitors* & $1.60(1.20-2.12)$ & $1.48(0.58-3.75)$ & $1.62(1.20-2.17)$ & $1.02(0.59-1.77)$ & $1.39(0.62-3.11)$ \\
\hline Digoxin* & $1.38(1.02-1.87)$ & $2.99(1.19-7.53)$ & $1.32(0.96-1.81)$ & $1.11(0.60-2.06)$ & $2.15(0.96-4.84)$ \\
\hline \multicolumn{6}{|l|}{ Score Charlson } \\
\hline \multicolumn{6}{|l|}{$<4$ (reference) } \\
\hline$\geq 4$ & $1.77(1.31-2.39)$ & $1.35(0.52-3.48)$ & $1.77(1.30-2.41)$ & $0.80(0.46-1.39)$ & $1.72(0.74-4.01)$ \\
\hline \multicolumn{6}{|l|}{$\mathrm{CHA}_{2} \mathrm{DS}_{2}$-VASc score } \\
\hline \multicolumn{6}{|l|}{$<3$ (reference) } \\
\hline$\geq 3$ & $1.06(0.72-1.56)$ & $3.31(0.44-24.89)$ & $1.01(0.68-1.50)$ & $0.76(0.38-1.52)$ & $4.48(0.60-33.14)$ \\
\hline \multicolumn{6}{|l|}{ HAS-BLED score } \\
\hline \multicolumn{6}{|l|}{$<3$ (reference) } \\
\hline$\geq 3$ & $1.22(0.92-1.62)$ & $0.83(0.31-2.20)$ & $1.28(0.95-1.72)$ & $1.05(0.60-1.84)$ & $2.33(1.04-2.25)$ \\
\hline Lenght of stay & $1.01(0.99-1.02)$ & $1.02(0.98-1.06)$ & $1.01(0.99-1.02)$ & $1.00(0.97-1.03)$ & $1.00(0.96-1.04)$ \\
\hline
\end{tabular}

Values are presented as hazard ratio (95\% confidence interval).

$\mathrm{SE}$, systemic embolism; OAC, oral anticoagulant; TIA, transient ischemic attack; ICH, intracranial hemorrhage; NSAID, nonsteroidal anti-inflammatory drug. ${ }^{*} 1=y e s$ vs. $0=$ no. 
Supplementary Table 6. Adjusted hazard ratios of clinical outcomes with a quarantine period of 6 weeks with binary time-dependent exposure (full cohort)

\begin{tabular}{|c|c|c|c|c|c|}
\hline & $\begin{array}{c}\text { Stroke/SE/death } \\
\text { (185 events) }\end{array}$ & $\begin{array}{l}\text { Stroke/SE } \\
\text { (17 events) }\end{array}$ & $\begin{array}{c}\text { Death } \\
\text { (174 events) }\end{array}$ & $\begin{array}{c}\text { Recurrent intracranial } \\
\text { bleeding } \\
\text { (48 events) }\end{array}$ & $\begin{array}{c}\text { Major extracranial } \\
\text { bleeding } \\
\text { (21 events) }\end{array}$ \\
\hline \multicolumn{6}{|l|}{ Exposure to $\mathrm{OAC}$} \\
\hline \multicolumn{6}{|l|}{ No treatment (reference) } \\
\hline Treatment & $0.10(0.05-0.21)$ & $0.56(0.16-1.96)$ & $0.07(0.03-0.17)$ & $0.43(0.19-0.97)$ & $1.73(0.71-4.20)$ \\
\hline \multicolumn{6}{|l|}{ Age (yr) } \\
\hline \multicolumn{6}{|l|}{ 65-74 (reference) } \\
\hline$\geq 75$ & $2.21(1.13-4.33)$ & & $2.64(1.25-5.54)$ & $0.45(0.21-0.94)$ & $2.41(0.32-18.10)$ \\
\hline \multicolumn{6}{|l|}{ Sex } \\
\hline \multicolumn{6}{|l|}{ Male (reference) } \\
\hline Female & $0.69(0.49-0.95)$ & $6.24(1.43-27.28)$ & $0.61(0.44-0.86)$ & $1.20(0.67-2.16)$ & $2.28(0.88-5.90)$ \\
\hline Prior stroke/TIA/SE* & $1.21(0.68-2.14)$ & $0.73(0.10-5.49)$ & $1.24(0.70-2.21)$ & & \\
\hline Prior major bleeding (except ICH)* & $0.94(0.57-1.55)$ & & $0.89(0.53-1.50)$ & $1.98(0.81-4.83)$ & $4.27(1.65-11.05)$ \\
\hline Chronic heart failure $^{*}$ & $1.40(1.01-1.94)$ & & $1.53(1.09-2.15)$ & & \\
\hline Peripheral artery disease ${ }^{*}$ & $0.98(0.69-1.39)$ & & $1.04(0.73-1.50)$ & & \\
\hline Chronic kidney disease* & $1.30(0.92-1.85)$ & & $1.26(0.88-1.80)$ & & \\
\hline Hypertension* & $0.90(0.57-1.40)$ & & $0.85(0.54-1.35)$ & $0.82(0.37-1.81)$ & \\
\hline Dyslipidemia* & $0.94(0.66-1.35)$ & & $0.91(0.63-1.32)$ & & \\
\hline Diabetes* & $1.23(0.89-1.71)$ & & $1.24(0.88-1.75)$ & $0.63(0.30-1.31)$ & \\
\hline Beta-blockers* & $1.18(0.87-1.61)$ & & $1.25(0.90-1.72)$ & & \\
\hline Statins* & $0.73(0.51-1.04)$ & & $0.69(0.48-0.99)$ & & \\
\hline Proton-pump inhibitors* & $1.44(1.05-1.97)$ & & $1.47(1.06-2.03)$ & & \\
\hline Digoxin* & $1.53(1.11-2.11)$ & & $1.47(1.05-2.06)$ & & \\
\hline \multicolumn{6}{|l|}{ Score Charlson } \\
\hline \multicolumn{6}{|l|}{$<4$ (reference) } \\
\hline$\geq 4$ & $1.33(0.89-1.99)$ & & $1.27(0.84-1.93)$ & $1.06(0.57-1.96)$ & \\
\hline \multicolumn{6}{|l|}{$\mathrm{CHA}_{2} \mathrm{DS}_{2}$-VASc score } \\
\hline \multicolumn{6}{|l|}{$<3$ (reference) } \\
\hline$\geq 3$ & $0.93(0.57-1.52)$ & & $0.89(0.53-1.47)$ & & \\
\hline \multicolumn{6}{|l|}{ HAS-BLED score } \\
\hline \multicolumn{6}{|l|}{$<3$ (reference) } \\
\hline$\geq 3$ & $1.03(0.72-1.49)$ & & $1.12(0.77-1.64)$ & $0.87(0.45-1.68)$ & \\
\hline
\end{tabular}

Values are presented as hazard ratio (95\% confidence interval).

$\mathrm{SE}$, systemic embolism; OAC, oral anticoagulant; TIA, transient ischemic attack; ICH, intracranial hemorrhage.

${ }^{*} 1=$ yes vs. $0=$ no. 
Supplementary Table 7. Adjusted hazard ratios of clinical outcomes with a quarantine period of 6 weeks with binary time-dependent exposure and categorical exposure

\begin{tabular}{|c|c|c|c|c|c|}
\hline & $\begin{array}{l}\text { Stroke/SE/death } \\
\text { (185 events) }\end{array}$ & $\begin{array}{c}\text { Stroke/SE } \\
\text { (17 events) }\end{array}$ & $\begin{array}{c}\text { Death } \\
\text { (174 events) }\end{array}$ & $\begin{array}{c}\text { Recurrent intracranial } \\
\text { bleeding } \\
\text { (48 events) }\end{array}$ & $\begin{array}{c}\text { Major extracranial } \\
\text { bleeding } \\
(21 \text { events })\end{array}$ \\
\hline \multicolumn{6}{|l|}{ Exposure to OACs } \\
\hline \multicolumn{6}{|l|}{ 0\% (reference) } \\
\hline$\%<90+$ current not exposed & $2.43(1.56-3.78)$ & $2.55(0.57-11.45)$ & $2.43(1.55-3.82)$ & $1.00(0.30-3.26)$ & $3.36(0.92-12.22)$ \\
\hline$\%<90+$ current exposed & $0.25(0.10-0.60)$ & - & $0.26(0.11-0.64)$ & $0.50(0.15-1.62)$ & $2.41(0.76-7.60)$ \\
\hline$\% \geq 90$ & $0.10(0.04-0.24)$ & $0.87(0.24-3.11)$ & $0.04(0.01-0.17)$ & $0.38(0.13-1.08)$ & $1.01(0.28-3.68)$ \\
\hline \multicolumn{6}{|l|}{ Age (yr) } \\
\hline \multicolumn{6}{|l|}{ 65-74 (reference) } \\
\hline$\geq 75$ & $2.38(1.21-4.67)$ & & $2.85(1.35-6.01)$ & $0.47(0.23-0.99)$ & \\
\hline \multicolumn{6}{|l|}{ Sex } \\
\hline \multicolumn{6}{|l|}{ Male (reference) } \\
\hline Female & $0.67(0.48-0.94)$ & $6.29(1.44-27.50)$ & $0.60(0.43-0.85)$ & $1.20(0.67-2.14)$ & \\
\hline Prior stroke/TIA/SE* & $1.18(0.67-2.09)$ & & $1.21(0.68-2.15)$ & & \\
\hline Prior major bleeding (except ICH) ${ }^{*}$ & $0.88(0.53-1.46)$ & & $0.84(0.50-1.41)$ & $2.04(0.83-5.01)$ & $3.70(1.42-9.63)$ \\
\hline Chronic heart failure $^{*}$ & $1.39(1.00-1.92)$ & & $1.52(1.09-2.14)$ & & \\
\hline Peripheral artery disease ${ }^{*}$ & $0.96(0.68-1.37)$ & & $1.03(0.72-1.48)$ & & \\
\hline Chronic kidney disease $^{*}$ & $1.33(0.94-1.89)$ & & $1.29(0.89-1.85)$ & & \\
\hline Hypertension* & $0.90(0.58-1.41)$ & & $0.85(0.54-1.35)$ & & \\
\hline Dyslipidemia* & $0.89(0.62-1.27)$ & & $0.85(0.59-1.24)$ & & \\
\hline Diabetes* & $1.27(0.91-1.76)$ & & $1.28(0.91-1.80)$ & & \\
\hline Beta-blockers* & $1.17(0.86-1.60)$ & & $1.24(0.89-1.71)$ & & \\
\hline Statins* & $0.72(0.50-1.03)$ & & $0.68(0.47-0.98)$ & & \\
\hline Proton-pump inhibitors* & $1.40(1.02-1.92)$ & & $1.42(1.02-1.97)$ & & \\
\hline Digoxin* & $1.49(1.08-2.05)$ & & $1.43(1.02-2.01)$ & & \\
\hline \multicolumn{6}{|l|}{ Score Charlson } \\
\hline \multicolumn{6}{|l|}{$<4$ (reference) } \\
\hline$\geq 4$ & $1.32(0.88-1.97)$ & & $1.26(0.83-1.92)$ & $0.90(0.51-1.61)$ & \\
\hline \multicolumn{6}{|l|}{$\mathrm{CHA}_{2} \mathrm{DS}_{2}$-VASc score } \\
\hline \multicolumn{6}{|l|}{$<3$ (reference) } \\
\hline$\geq 3$ & $0.93(0.57-1.53)$ & & $0.89(0.53-1.47)$ & & \\
\hline \multicolumn{6}{|l|}{ HAS-BLED } \\
\hline \multicolumn{6}{|l|}{$<3$ (reference) } \\
\hline$\geq 3$ & $1.05(0.73-1.52)$ & & $1.14(0.78-1.66)$ & $0.82(0.43-1.57)$ & \\
\hline
\end{tabular}

Values are presented as hazard ratio (95\% confidence interval).

$\mathrm{SE}$, systemic embolism; OAC, oral anticoagulant; TIA, transient ischemic attack; ICH, intracranial hemorrhage.

${ }^{*} 1=$ yes vs. $0=$ no. 
Supplementary Table 8. Adjusted hazard ratios of all-cause mortality with a quarantine period of 6 weeks with binary time-dependent exposure and timedependent covariates

\begin{tabular}{|c|c|}
\hline & Death (174 events) \\
\hline \multicolumn{2}{|l|}{ Exposure to OACs } \\
\hline \multicolumn{2}{|l|}{ No exposure (reference) } \\
\hline Exposure & $0.07(0.03-0.17)$ \\
\hline Stroke/SE* & $3.75(1.58-8.91)$ \\
\hline Recurrent intracranial bleeding* & $1.95(1.13-3.37)$ \\
\hline Major extracranial bleeding* & $1.96(0.89-4.29)$ \\
\hline \multicolumn{2}{|l|}{ Age (yr) } \\
\hline \multicolumn{2}{|l|}{ 65-74 (reference) } \\
\hline$\geq 75$ & $2.67(1.26-5.62)$ \\
\hline \multicolumn{2}{|l|}{ Sex } \\
\hline \multicolumn{2}{|l|}{ Male (reference) } \\
\hline Female & $0.57(0.41-0.81)$ \\
\hline Prior stroke/TIA/SE* & $1.20(0.67-2.15)$ \\
\hline Prior major bleeding (except ICH)* & $0.84(0.50-1.41)$ \\
\hline Chronic heart failure* & $1.61(1.15-2.26)$ \\
\hline Peripheral artery disease ${ }^{*}$ & $1.06(0.74-1.53)$ \\
\hline Chronic kidney disease $^{*}$ & $1.23(0.85-1.77)$ \\
\hline Hypertension* & $0.81(0.51-1.29)$ \\
\hline Dyslipidemia* & $0.90(0.62-1.31)$ \\
\hline Diabetes* & $1.22(0.87-1.72)$ \\
\hline Beta-blockers* & $1.22(0.88-1.70)$ \\
\hline Statins* & $0.68(0.47-0.98)$ \\
\hline Proton-pump inhibitors* & $1.45(1.05-2.01)$ \\
\hline Digoxin* & $1.43(1.02-2.00)$ \\
\hline \multicolumn{2}{|l|}{ Score Charlson } \\
\hline \multicolumn{2}{|l|}{$<4$ (reference) } \\
\hline$\geq 4$ & $1.24(0.81-1.89)$ \\
\hline \multicolumn{2}{|l|}{$\mathrm{CHA}_{2} \mathrm{DS}_{2}$-VASc score } \\
\hline \multicolumn{2}{|l|}{$<3$ (reference) } \\
\hline$\geq 3$ & $0.91(0.55-1.51)$ \\
\hline \multicolumn{2}{|l|}{ HAS-BLED } \\
\hline \multicolumn{2}{|l|}{$<3$ (reference) } \\
\hline$\geq 3$ & $1.17(0.80-1.71)$ \\
\hline
\end{tabular}

Values are presented as hazard ratio (95\% confidence interval).

$\mathrm{OAC}$, oral anticoagulant; $\mathrm{SE}$, systemic embolism; TIA, transient ischemic attack; ICH, intracranial hemorrhage.

${ }^{*} 1=$ yes vs. $0=$ no. 
Supplementary Table 9. Definition of subgroup analysis (e.g., spontaneous and traumatic ICH) ${ }^{17}$

\begin{tabular}{|c|c|}
\hline \multicolumn{2}{|c|}{ Total spontaneous ICH events $(n=394)$} \\
\hline ICD-9 codes $(n=74)$ & ICD-10 codes $(n=320)$ \\
\hline 430 subarachnoid hemorrhage $(n=2)$ & I60 subarachnoid hemorrhage $(n=28)$ \\
\hline 431 intracerebral hemorrhage $(n=47)$ & I61 intracerebral hemorrhage, unspecified $(n=193)$ \\
\hline 432 extradural hemorrhage $(n=25)$ & I62 extradural hemorrhage $(n=99)$ \\
\hline \multicolumn{2}{|c|}{ Total traumatic ICH events $(n=309)$} \\
\hline ICD-9 codes $(n=41)$ & ICD-10 codes ( $n=268)$ \\
\hline 852.X $(n=29)$ & S06.3; traumatic intracranial hemorrhage $(n=39)$ \\
\hline \multicolumn{2}{|c|}{$\begin{array}{l}\text { Subarachnoid hemorrhage following injury without open intracranial wound } \pm \text { consciousness } \\
\text { Subarachnoid hemorrhage following injury without open intracranial wound } \pm \text { consciousness } \\
\text { Subarachnoid hemorrhage following injury without open intracranial wound } \pm \text { consciousness }\end{array}$} \\
\hline 853.X $(n=12)$ & S06.4; traumatic epidural hemorrhage $(n=4)$ \\
\hline \multicolumn{2}{|c|}{$\begin{array}{l}\text { Other and unspecified intracranial hemorrhage following injury without open intracranial } \\
\text { wound } \pm \text { consciousness }\end{array}$} \\
\hline & S06.5; traumatic subdural hemorrhage $(n=156)$ \\
\hline & S06.6; traumatic subarachnoid hemorrhage $(n=69)$ \\
\hline
\end{tabular}


Supplementary Table 10. Baseline characteristics of full cohort for a quarantine period of 6 weeks according drug exposure categories

\begin{tabular}{|c|c|c|c|c|}
\hline Characteristic & $\begin{array}{l}\text { No treatment } \\
(n=423)\end{array}$ & $\begin{array}{l}\text { OAC exposure } \\
(n=260)\end{array}$ & $\begin{array}{l}\text { OAC partial exposure } \\
(n=144)\end{array}$ & $\begin{array}{l}\text { OAC continuous exposure } \\
\qquad(n=116)\end{array}$ \\
\hline \multicolumn{5}{|l|}{ Sociodemographics* } \\
\hline Age (yr) & $83.6 \pm 5.8$ & $81.7 \pm 5.8$ & $81.6 \pm 6.1^{+}$ & $81.9 \pm 5.4^{\ddagger}$ \\
\hline Male sex & $200(47.3)$ & $120(46.1)$ & $64(44.4)$ & $56(48.3)$ \\
\hline \multicolumn{5}{|l|}{ Prior exposure (3-mo prior ICH index) } \\
\hline Anticoagulants & $292(69.0)$ & 233 (89.6) & $127(88.2)^{+}$ & $106(91.4)^{\dagger}$ \\
\hline Warfarine & $280(66.2)$ & $214(82.3)$ & $116(80.6)^{+}$ & $98(84.5)^{\ddagger}$ \\
\hline DOACs & $14(3.3)$ & $21(8.1)$ & $12(8.3)^{+}$ & $9(7.8)^{*}$ \\
\hline Antiplatelet agents & $167(39.5)$ & $83(31.9)$ & $52(36.1)$ & $31(26.7)^{+}$ \\
\hline ASA low dose & $155(36.6)$ & $74(28.5)$ & 45 (31.2) & $29(25.0)^{7}$ \\
\hline Clopidrogrel & $27(6.4)$ & $18(6.9)$ & $13(9.0)$ & $5(4.3)$ \\
\hline \multicolumn{5}{|l|}{ Co-morbidities (ICH index and 1-yr prior) } \\
\hline Hypertension & $366(86.5)$ & $218(83.8)$ & $122(84.7)$ & 96 (82.8) \\
\hline Dyslipidemia & $152(35.9)$ & $130(50.0)$ & $72(50.0)^{+}$ & $58(50.0)^{7}$ \\
\hline Diabetes & $130(30.7)$ & $81(31.1)$ & $36(25.0)$ & $45(38.8)$ \\
\hline Coronary artery disease & $272(64.3)$ & $168(64.6)$ & $92(63.9)$ & $76(65.5)$ \\
\hline Acute myocardial infarction & $27(6.4)$ & $21(8.1)$ & $14(9.7)$ & $7(6.0)$ \\
\hline Chronic heart failure & $147(34.7)$ & $104(40.0)$ & $52(36.1)$ & $52(44.8)^{+}$ \\
\hline Cerebrovascular disease including TIA in 5-yr period & $231(54.6)$ & $129(49.6)$ & $70(48.6)$ & $59(50.9)$ \\
\hline Peripheral vascular disease & $85(20.1)$ & $65(25.0)$ & $32(22.2)$ & $33(28.4)$ \\
\hline Chronic renal failure & $168(39.7)$ & $105(40.4)$ & $53(36.8)$ & $52(44.8)$ \\
\hline Acute renal failure & $75(17.7)$ & $40(15.4)$ & $21(14.6)$ & $19(16.4)$ \\
\hline Chronic obstructive pulmonary disease/asthma & $130(30.7)$ & $78(30.0)$ & $38(26.4)$ & $40(34.5)$ \\
\hline Prior major bleeding (excluding ICH) in 5-yr period & $39(9.2)$ & $27(10.4)$ & $16(11.1)$ & $11(9.5)$ \\
\hline Liver disease & $10(2.4)$ & $7(2.7)$ & $3(2.1)$ & $4(3.4)$ \\
\hline Systemic embolism & $5(1.2)$ & $5(1.9)$ & $4(2.8)$ & $1(0.9)$ \\
\hline \multicolumn{5}{|l|}{ Medications (3-mo prior ICH index) $)^{\S}$} \\
\hline$\beta$-Blockers & $245(57.9)$ & $157(60.4)$ & $84(58.3)$ & $73(62.9)$ \\
\hline Calcium channel blockers & $161(38.1)$ & $109(41.9)$ & $57(39.6)$ & $52(44.8)$ \\
\hline Inhibitors of renin-angiotensin system & $206(48.7)$ & $126(48.5)$ & $67(46.5)$ & 59 (50.9) \\
\hline Diuretics & $229(54.1)$ & $152(58.5)$ & $81(56.2)$ & $71(61.2)$ \\
\hline Loop diuretics & $193(45.6)$ & $122(46.9)$ & 66 (45.8) & $56(48.3)$ \\
\hline Statin & $202(47.7)$ & $149(57.3)$ & $81(56.2)$ & $68(58.6)^{\dagger}$ \\
\hline Antidiabetics & $98(23.2)$ & $69(26.5)$ & $32(22.2)$ & 37 (31.9) \\
\hline Antidepressants & $105(24.8)$ & $56(21.5)$ & 27 (18.7) & $29(25.0)$ \\
\hline Proton pump inhibitors & $198(46.8)$ & $132(50.8)$ & $68(47.2)$ & $64(55.2)$ \\
\hline Digoxin & $99(23.4)$ & $80(30.8)$ & $44(30.6)$ & $36(31.0)$ \\
\hline Amiodarone & $49(11.6)$ & $39(15.0)$ & $21(14.6)$ & 18 (15.5) \\
\hline $\mathrm{CHA}_{2} \mathrm{DS}_{2}$-VASc score $(\mathrm{ICH} \text { index and 1-yr prior })^{\S}$ & $3.9 \pm 1.3$ & $3.9 \pm 1.3$ & $3.9 \pm 1.3$ & $3.9 \pm 1.3$ \\
\hline 1 & $1(0.2)$ & $7(2.7)$ & $5(3.5)^{+}$ & $2(1.7)$ \\
\hline 2 & $53(12.5)$ & $20(7.7)$ & $9(6.3)^{+}$ & $11(9.5)$ \\
\hline 3 & $110(26.0)$ & $72(27.7)$ & $43(29.9)^{+}$ & $29(25.0)$ \\
\hline $4-9$ & $259(61.2)$ & $161(61.9)$ & $87(60.4)^{+}$ & 74 (63.8) \\
\hline
\end{tabular}


Supplementary Table 10. Continued

\begin{tabular}{|c|c|c|c|c|}
\hline Characteristic & $\begin{array}{l}\text { No treatment } \\
\quad(n=423)\end{array}$ & $\begin{array}{l}\text { OAC exposure } \\
(n=260)\end{array}$ & $\begin{array}{l}\text { OAC partial exposure } \\
(n=144)\end{array}$ & $\begin{array}{l}\text { OAC continuous exposure } \\
\qquad(n=116)\end{array}$ \\
\hline HAS-BLED score (ICH index and 1-yr prior)" & $2.6 \pm 1.1$ & $2.6 \pm 1.1$ & $2.7 \pm 1.1$ & $2.6 \pm 1.1$ \\
\hline$<3.0$ & $219(51.8)$ & $141(54.2)$ & $74(51.4)$ & $67(57.8)$ \\
\hline$\geq 3.0$ & $204(48.2)$ & $119(45.8)$ & 70 (48.6) & $49(42.2)$ \\
\hline \multicolumn{5}{|l|}{ Charlson score (ICH index and 1-yr prior index) $)^{5}$} \\
\hline Mean \pm SD & $4.5 \pm 3.2$ & $4.3 \pm 3.2$ & $4.1 \pm 3.4$ & $4.6 \pm 3.1$ \\
\hline Median (interquartile range) & $4.0(2.0-6.0)$ & $4.0(2.0-6.0)$ & $4.0(2.0-5.0)$ & $4.0(2.0-6.0)$ \\
\hline \multicolumn{5}{|l|}{ Health medical service $(1-y r \text { prior ICH index })^{\S}$} \\
\hline No. of of specialty visits & $9.9 \pm 19.3$ & $9.3 \pm 14.8$ & $9.7 \pm 14.1^{+}$ & $8.8 \pm 15.6$ \\
\hline No. of of family physician visits & $3.2 \pm 6.0$ & $2.7 \pm 4.4$ & $2.6 \pm 4.0$ & $2.9 \pm 4.9$ \\
\hline No. of of emergency visits & $3.9 \pm 3.8$ & $3.6 \pm 3.6$ & $3.6 \pm 3.6$ & $3.6 \pm 3.7$ \\
\hline \multicolumn{5}{|l|}{ Health hospital service $(3-y r \text { prior ICH index) })^{\S}$} \\
\hline Proportion of all-cause hospital admission & $360(85.1)$ & $226(86.9)$ & $129(89.6)$ & $97(83.6)$ \\
\hline No. of of all-cause hospital admission & $2.7 \pm 2.4$ & $2.7 \pm 2.5$ & $2.6 \pm 2.4$ & $2.7 \pm 2.6$ \\
\hline Hospital length of stay & $11.2 \pm 10.8$ & $7.5 \pm 6.9$ & $7.0 \pm 6.6^{+}$ & $8.1 \pm 7.3^{\ddagger}$ \\
\hline
\end{tabular}

Values are presented as mean \pm standard deviation or number (\%) unless otherwise indicated.

$O A C$, oral anticoagulant; ICH, intracranial hemorrhage; DOAC, direct oral anticoagulant; $A S A$, acetylsalicylic acid; TIA, transient ischemic attack.

${ }^{*}$ At the cohort entry; ${ }^{+} \mathrm{P}<0.05$ in the comparison between the no OAC and the OAC partial exposure group; ${ }^{*} \mathrm{P}<0.05$ in the comparison between the no $0 A C$ and the OAC continuous exposure group; ${ }^{\S}$ Data source: Régie de l'Assurance Maladie du Quebec (RAMQ) dataset; "The components of the scores are provided in Supplementary Tables. 
Supplementary Table 11. Crude and adjusted hazard ratios of clinical outcomes with binary time-dependent exposure in the spontaneous and traumatic ICH

\begin{tabular}{|c|c|c|c|c|c|}
\hline & Stroke/SE/death & Stroke/SE & Death & $\begin{array}{c}\text { Recurrent intracranial } \\
\text { bleeding }\end{array}$ & $\begin{array}{c}\text { Major extracranial } \\
\text { bleeding }\end{array}$ \\
\hline \multicolumn{6}{|l|}{ Spontaneous ICH } \\
\hline Number & 372 & 372 & 371 & 372 & 371 \\
\hline Events & 106 & 8 & 100 & 27 & 11 \\
\hline No exposure & Reference & Reference & Reference & Reference & Reference \\
\hline \multicolumn{6}{|l|}{ Exposure to OACs } \\
\hline Crude hazard ratio & $0.12(0.04-0.32)$ & $0.42(0.05-3.42)$ & $0.09(0.03-0.29)$ & $0.38(0.12-1.28)$ & $1.68(0.49-5.78)$ \\
\hline Adjusted hazard ratio & $0.10(0.04-0.27)$ & $0.45(0.05-3.65)$ & $0.08(0.03-0.25)$ & $0.34(0.10-1.14)$ & $1.67(0.48-5.79)$ \\
\hline \multicolumn{6}{|l|}{ Traumatic ICH } \\
\hline Number & 310 & 310 & 310 & 311 & 310 \\
\hline Events & 79 & 9 & 74 & 21 & 10 \\
\hline No exposure & Reference & Reference & Reference & Reference & Reference \\
\hline \multicolumn{6}{|l|}{ Exposure to OACs } \\
\hline Crude hazard ratio & $0.11(0.04-0.30)$ & $0.58(0.12-2.82)$ & $0.06(0.01-0.23)$ & $0.53(0.18-1.58)$ & $1.51(0.42-5.39)$ \\
\hline Adjusted hazard ratio & $0.11(0.04-0.30)$ & $0.61(0.13-2.94)$ & $0.06(0.01-0.23)$ & $0.53(0.18-1.60)$ & $1.66(0.46-5.97)$ \\
\hline
\end{tabular}

Values are presented as hazard ratio (95\% confidence interval).

$\mathrm{ICH}$, intracranial hemorrhage; $\mathrm{SE}$, systemic embolism; OAC, oral anticoagulant. 
Supplementary Table 12. Crude and adjusted hazard ratios of clinical outcomes with binary time-dependent exposure in the age population older $\geq 75$ and $<75$ years

\begin{tabular}{|c|c|c|c|c|c|}
\hline & Stroke/SE/death & Stroke/SE & Death & $\begin{array}{c}\text { Recurrent intracranial } \\
\text { bleeding }\end{array}$ & $\begin{array}{c}\text { Major extracranial } \\
\text { bleeding }\end{array}$ \\
\hline \multicolumn{6}{|l|}{ Population $\geq 75 \mathrm{yr}$} \\
\hline Number & 608 & 608 & 607 & 609 & 607 \\
\hline Events & 175 & 15 & 166 & 39 & 20 \\
\hline No exposure & Reference & Reference & Reference & Reference & Reference \\
\hline \multicolumn{6}{|l|}{ Exposure to OACs } \\
\hline Crude hazard ratio & $0.08(0.03-0.19)$ & $0.19(0.02-1.45)$ & $0.06(0.02-0.17)$ & $0.50(0.21-1.20)$ & $1.48(0.59-3.73)$ \\
\hline Adjusted hazard ratio & $0.07(0.03-0.17)$ & $0.20(0.03-1.50)$ & $0.06(0.02-0.16)$ & $0.50(0.21-1.19)$ & $1.52(0.61-3.84)$ \\
\hline \multicolumn{6}{|l|}{ Population $<75 \mathrm{yr}$} \\
\hline Number & 74 & 74 & 74 & 74 & 74 \\
\hline Events & 10 & 2 & 8 & 9 & 1 \\
\hline No exposure & Reference & Reference & Reference & Reference & Reference \\
\hline \multicolumn{6}{|l|}{ Exposure to OACs } \\
\hline Crude hazard ratio & $0.74(0.19-2.92)$ & $\mathrm{n}$ to small & $0.26(0.03-2.16)$ & $0.24(0.03-1.98)$ & $\mathrm{n}$ to small \\
\hline Adjusted hazard ratio & $0.26(0.04-1.66)$ & $\mathrm{n}$ to small & $0.03(0.01-1.02)$ & $0.27(0.03-2.46)$ & $\mathrm{n}$ to small \\
\hline
\end{tabular}

Values are presented as hazard ratio (95\% confidence interval).

$\mathrm{SE}$, systemic embolism; OAC, oral anticoagulant. 
Supplementary Table 13. Net clinical benefit of the combination of ischemic stroke and systemic embolism and ICH

\begin{tabular}{|c|c|c|c|c|c|c|c|c|c|c|}
\hline \multirow{3}{*}{ Type of diagnosis } & \multicolumn{5}{|c|}{ TE } & \multicolumn{5}{|c|}{$\mathrm{ICH}$} \\
\hline & \multicolumn{2}{|c|}{ Not receiving $\mathrm{OACs}$} & \multicolumn{2}{|c|}{$\begin{array}{c}\text { Receiving exposure to all } \\
\text { OACs }\end{array}$} & \multirow{2}{*}{$\begin{array}{l}\text { Difference } \\
\text { - in rate of TE- } \\
\text { (off-on) }\end{array}$} & \multicolumn{2}{|c|}{ Not receiving OACs } & \multicolumn{2}{|c|}{$\begin{array}{l}\text { Receiving exposure to all } \\
\text { OACs }\end{array}$} & \multirow{2}{*}{$\begin{array}{c}\text { Difference } \\
\text { in rate of } \\
\mathrm{ICH} \\
\text { (on-off) }\end{array}$} \\
\hline & PY & $\begin{array}{l}\text { Annual rate } \\
\text { per } 100 \mathrm{PY}\end{array}$ & PY & $\begin{array}{l}\text { Annual rate } \\
\text { per } 100 \text { PY }\end{array}$ & & PY & $\begin{array}{c}\text { Annual rate } \\
\text { per } 100 \mathrm{PY}\end{array}$ & PY & $\begin{array}{l}\text { Annual rate } \\
\text { per } 100 \mathrm{PY}\end{array}$ & \\
\hline Total cohort & 331.9 & 3.3 & 235.0 & 2.6 & 0.7 & 315.7 & 11.4 & 229.5 & 5.2 & -6.2 \\
\hline Non-traumatic diagnosis & 193.4 & 3.6 & 113.0 & 0.9 & 2.7 & 185.7 & 12.4 & 109.6 & 3.6 & -8.8 \\
\hline Traumatic diagnosis & 138.4 & 2.9 & 122.0 & 4.1 & -1.5 & 130.0 & 10.0 & 119.9 & 6.7 & -3.3 \\
\hline Annual net clinical benefit & \multicolumn{3}{|c|}{ Weight $=1.5$} & \multicolumn{2}{|r|}{ Weight=1.0 } & \multicolumn{5}{|c|}{ Weight $=2.0$} \\
\hline Total cohort & \multicolumn{3}{|c|}{$10.3(10.1-10.5)$} & \multicolumn{2}{|r|}{$7.1(6.9-7.3)$} & \multicolumn{5}{|c|}{$13.5(13.2-13.8)$} \\
\hline Non-traumatic diagnosis & \multicolumn{3}{|c|}{$16.3(16.0-16.6)$} & \multicolumn{2}{|c|}{$11.8(11.5-12.0)$} & \multicolumn{5}{|c|}{$20.8(20.4-21.2)$} \\
\hline Traumatic diagnosis & \multicolumn{3}{|c|}{$3.8(3.4-4.2)$} & \multicolumn{2}{|r|}{$2.1(1.9-2.4)$} & \multicolumn{5}{|c|}{$5.5(5.0-6.0)$} \\
\hline
\end{tabular}

Values are presented as annual net clinical benefit (95\% confidence interval).

$\mathrm{ICH}$, intracranial hemorrhage; $\mathrm{TE}$, thromboembolism; $\mathrm{OAC}$, oral anticoagulant; $\mathrm{PY}$, person-year. 
Supplementary Table 14. Net clinical benefit of the combination of death and ICH

\begin{tabular}{|c|c|c|c|c|c|c|c|c|c|c|}
\hline \multirow{3}{*}{ Type of diagnosis } & \multicolumn{5}{|c|}{ All-cause death } & \multicolumn{5}{|c|}{$\mathrm{ICH}$} \\
\hline & \multicolumn{2}{|c|}{ Not receiving OACs } & \multicolumn{2}{|c|}{$\begin{array}{c}\text { Receiving exposure to all } \\
\text { OACs }\end{array}$} & \multirow{2}{*}{$\begin{array}{c}\text { Difference } \\
\text { in rate of } \\
\text { death (off- } \\
\text { on) }\end{array}$} & \multicolumn{2}{|c|}{ Not receiving OACs } & \multicolumn{2}{|c|}{$\begin{array}{c}\text { Receiving exposure to all } \\
\text { OACs }\end{array}$} & \multirow{2}{*}{$\begin{array}{c}\text { Difference } \\
\text { in rate of } \\
\text { ICH } \\
\text { (on-off) }\end{array}$} \\
\hline & PY & $\begin{array}{c}\text { Annual rate } \\
\text { per } 100 \mathrm{PY}\end{array}$ & PY & $\begin{array}{c}\text { Annual rate } \\
\text { per } 100 \mathrm{PY}\end{array}$ & & PY & $\begin{array}{c}\text { Annual rate } \\
\text { per } 100 \text { PY }\end{array}$ & PY & $\begin{array}{c}\text { Annual rate } \\
\text { per } 100 \mathrm{PY}\end{array}$ & \\
\hline Total cohort & 332.8 & 40.6 & 239.6 & 16.3 & 24.3 & 315.7 & 11.4 & 229.5 & 5.2 & -6.2 \\
\hline Non-traumatic diagnosis & 195.2 & 41.0 & 113.3 & 17.7 & 23.3 & 185.7 & 12.4 & 109.6 & 3.6 & -8.8 \\
\hline Traumatic diagnosis & 137.6 & 40.0 & 126.3 & 15.0 & 25.0 & 130.0 & 10.0 & 119.9 & 6.7 & -3.3 \\
\hline Annual net clinical benefit & \multicolumn{3}{|c|}{ Weight $=1.5$} & \multicolumn{3}{|c|}{ Weight $=1.0$} & \multicolumn{3}{|c|}{ Weight $=2.0$} & \\
\hline Total cohort & \multicolumn{3}{|c|}{$34.1(33.7-34.5)$} & \multicolumn{3}{|c|}{$30.9(30.6-31.3)$} & \multicolumn{3}{|c|}{$37.3(36.9-37.8)$} & \\
\hline Non-traumatic diagnosis & \multicolumn{3}{|c|}{$37.1(36.6-37.7)$} & \multicolumn{3}{|c|}{$32.6(32.2-33.1)$} & \multicolumn{3}{|c|}{$41.7(41.1-42.3)$} & \\
\hline Traumatic diagnosis & \multicolumn{3}{|c|}{$30.2(29.6-30.7)$} & \multicolumn{3}{|c|}{$28.5(28.0-29.0)$} & \multicolumn{3}{|c|}{$31.9(31.2-32.5)$} & \\
\hline
\end{tabular}

Values are presented as annual net clinical benefit (95\% confidence interval).

$\mathrm{ICH}$, intracranial hemorrhage; $\mathrm{OAC}$, oral anticoagulant; PY, person-year. 
Supplementary Table 15. Net clinical benefit of the combination of death and extracranial major

\begin{tabular}{|c|c|c|c|c|c|c|c|c|c|c|}
\hline \multirow{3}{*}{ Type of diagnosis } & \multicolumn{5}{|c|}{ All-cause death } & \multicolumn{5}{|c|}{ Extracranial major bleeding } \\
\hline & \multicolumn{2}{|c|}{ Not receiving OACs } & \multicolumn{2}{|c|}{$\begin{array}{c}\text { Receiving all exposure to } \\
\text { OACS }\end{array}$} & \multirow{2}{*}{$\begin{array}{l}\text { Difference } \\
\text { in rate of } \\
\text { death (off- } \\
\text { on) }\end{array}$} & \multicolumn{2}{|c|}{$\begin{array}{l}\text { Not receiving } \\
\text { OACs }\end{array}$} & \multicolumn{2}{|c|}{$\begin{array}{c}\text { Receiving all exposure to } \\
\text { OACs }\end{array}$} & \multirow{2}{*}{$\begin{array}{c}\text { Difference } \\
\text { in rate of } \\
\text { ICH } \\
\text { (on-off) }\end{array}$} \\
\hline & PY & $\begin{array}{l}\text { Annual rate } \\
\text { per } 100 \mathrm{PY}\end{array}$ & PY & $\begin{array}{l}\text { Annual rate } \\
\text { per } 100 \mathrm{PY}\end{array}$ & & PY & $\begin{array}{l}\text { Annual rate } \\
\text { per } 100 \mathrm{PY}\end{array}$ & PY & $\begin{array}{l}\text { Annual rate } \\
\text { per } 100 \mathrm{PY}\end{array}$ & \\
\hline Total cohort & 332.8 & 40.6 & 239.6 & 16.3 & 24.3 & 328.9 & 2.7 & 231.2 & 5.2 & 2.5 \\
\hline Non-traumatic diagnosis & 195.2 & 41.0 & 113.3 & 17.7 & 23.3 & 192.4 & 3.1 & 110.5 & 4.5 & 1.4 \\
\hline Traumatic diagnosis & 137.6 & 40.0 & 126.3 & 15.0 & 25.0 & 136.5 & 2.2 & 120.7 & 5.8 & 3.6 \\
\hline Annual net clinical benefit & \multicolumn{3}{|c|}{ Weight $=1.5$} & \multicolumn{3}{|c|}{ Weight $=1.0$} & \multicolumn{3}{|c|}{ Weight $=2.0$} & \\
\hline Total cohort & \multicolumn{3}{|c|}{$21.0(20.6-21.3)$} & \multicolumn{3}{|c|}{$22.2(21.8-22.5)$} & \multicolumn{3}{|c|}{$19.8(19.4-20.1)$} & \\
\hline Non-traumatic diagnosis & \multicolumn{3}{|c|}{$21.4(20.9-21.8)$} & \multicolumn{3}{|c|}{$22.1(21.7-22.5)$} & \multicolumn{3}{|c|}{$20.6(20.1-21.1)$} & \\
\hline Traumatic diagnosis & \multicolumn{3}{|c|}{19.8 (19.3-20.3) } & \multicolumn{3}{|c|}{$21.6(21.1-22.0)$} & \multicolumn{3}{|c|}{$18.1(17.5-18.6)$} & \\
\hline
\end{tabular}

Values are presented as annual net clinical benefit (95\% confidence interval).

$\mathrm{OAC}$, oral anticoagulant; ICH, intracranial hemorrhage; $\mathrm{PY}$, person-year. 